\title{
Multiscale fiber-reinforced thermoplastic composites incorporating carbon nanotubes: A review
}

\author{
Ana M. Díez-Pascual ${ }^{\mathrm{a}, *}$, Mohammed Naffakh ${ }^{\mathrm{b}}$, Carlos Marco ${ }^{\mathrm{a}}$, Marián A. Gómez-Fatou ${ }^{\mathrm{a}}$, Gary J. Ellis ${ }^{\mathrm{a}}$ \\ ${ }^{a}$ Instituto de Ciencia y Tecnología de Polímeros, ICTP-CSIC, Juan de la Cierva 3, 28006 Madrid, Spain \\ ${ }^{\mathrm{b}}$ Universidad Politécnica de Madrid, Departamento de Ingeniería y Ciencia de los Materiales, Escuela Técnica Superior de Ingenieros Industriales, José Gutiérrez Abascal 2 , \\ 28006 Madrid, Spain
}

\section{Keywords:}

Carbon nanotubes

Hierarchical composites

Thermoplastic polymers

Synergistic effects

\begin{abstract}
A B S T R A C T
This article reviews recent literature on hierarchical thermoplastic-based composites that simultaneously incorporate carbon nanotubes (CNTs) and conventional microscale fibers, and discusses the structureproperty relationships of the resulting hybrids. The mixing of multiple and multiscale constituents enables the preparation of materials with new or improved properties due to synergistic effects. By exploiting the outstanding mechanical, thermal and electrical properties of CNTs, a new generation of multifunctional high-performance composites suitable for a wide variety of applications can be developed.
\end{abstract}

\section{Introduction}

Conventional continuous carbon fiber (CF) or glass fiber (GF)reinforced polymer composites have been developed over the past half-century to provide a wide range of materials that are lightweight and combine superior mechanical properties with chemical and environmental resistance, making them particularly attractive for many applications in aerospace [1], automotion [2], marine [3], sporting goods [4], civil infrastructures [5] and the energy sector, both alternative energy, e.g. wind turbine blades [6], and conventional energy generation, e.g. underground oil-drilling [7]. Although outstanding mechanical performance has been achieved through different fiber configurations using woven fabrics, unidirectional tapes have been mainly employed within the last years due to the enhanced stiffness-to-weight properties of the resulting composites and their automatic lay-up process. But the application of these composites is frequently limited by poor compressive properties and delamination resistance [8]. In fact, delamination may provoke severe reductions in the in-plane stiffness and strength, resulting in a catastrophic failure of the whole structure. It can be introduced by external loadings such as in static bending, compression or tension, in cyclic fatigue or by impacts of low-tohigh energies during manufacturing or in service. The most important factors contributing to delamination are the poor interlaminar properties of the weak fiber-matrix interface and the brittle nature of many polymer matrices. Many methods have been devised over the past three decades to solve this problem, like toughening the

\footnotetext{
* Corresponding author. Tel.: +34915622 900; fax: +34915644853.

E-mail address: adiez@ictp.csic.es (A.M. Díez-Pascual).
}

matrix resin with elastomers [9] and interleafing with tough polymers, short fibers, or metal layers $[10,11]$. Further, delamination can be reduced by introducing different through-thickness reinforcing strategies such as 3D textiles [12], stitching [13], z-pinning [14] and braiding $[15,16]$. However, such modifications of the composite structure do not serve to improve the fiber-matrix interfacial adhesion, and enhance the interlaminar fracture toughness and impact damage tolerance at the expense of in-plane mechanical properties [8]. On the other hand, the fiber-matrix interface can be strengthened by different approaches, including sizings [17], fiber surface treatments $[4,17,18]$ and coupling agents $[18,19]$. For design purposes these procedures need to be optimized, thus increasing the manufacturing cost. In addition, most of the abovementioned strategies can be difficult to scale up. Alternatively, delamination problems can be addressed on the nanoscale through the development of hierarchical (also denominated hybrid or multiscale) composites by surface modification of the fibers and/or toughening of the matrix with nanoreinforcements.

Carbon nanotubes (CNTs) have nanoscale dimensions with very high aspect ratio that leads to a combination of excellent mechanical, thermal and electronic properties, making them ideal candidates as fillers in polymer composites [20]. Several approaches have been reported to integrate CNTs into traditional fiber/polymer composites: infusion/impregnation of a CNT-resin mixture into the primary fiber assembly [21,22], direct growth of CNTs on reinforcement fabric substrates through chemical vapor deposition (CVD) $[23,24]$, direct placement of CNTs between layers of the preform [25], electrophoretic deposition (EPD) onto the surface of fabric layers $[26,27]$, reactions between functionalized CNTs and fibers [26], electrostatic assembly of oxidized CNTs onto functionalized 
fibers [28] and coating of fibers with CNT-containing sizes [29-32]. In all cases, the delamination resistance and out-of-plane properties were shown to improve through interactions between the propagating cracks and the CNTs through different mechanisms such as CNT debonding, crack deflection, crack pinning and CNT pull out [21]. Moreover, the addition of CNTs generally improves the thermo-mechanical properties of the composite, increasing the glass transition temperature $\left(T_{g}\right)$ of the matrix and decreasing its coefficient of thermal expansion [33]. The aforementioned methods have been explored primarily for CF-reinforced composites, although several studies have also been reported on the effect of adding CNTs to GF-reinforced matrices [28-40]. Further, only a few studies $[27,29,35,36,38-41]$ have explored the use of singlewalled carbon nanotubes (SWCNTs) in hierarchical composites, since they are more difficult to disperse and more expensive than multi-walled carbon nanotubes (MWCNTs). However, the very high surface area and modulus of SWCNTs are expected to generate larger enhancements in composite performance. To date, most of the literature related to hierarchical composites refers to thermoset resins, and reports on CNT-reinforced thermoplastics are relatively scarce [23,28-32,35-39,42-49] since manufacturing is still a major challenge due to their high viscosity. In this review, we will focus on this type of hierarchical composites based on a thermoplastic matrix and describe their morphology, thermal, mechanical and electrical properties. Examples have been selected to demonstrate the importance of mixing multiple and different scale constituents for developing new materials with enhanced properties due to synergistic effects. In this respect, the simultaneous addition of micro- and nano-scale fillers leads to improvements that are larger than the sum of the effect of each type of reinforcement. Finally, potential applications and future perspectives of these multiscale hybrid composites will be discussed.

\section{Conventional fiber-reinforced thermoplastic composites}

In order to assess the benefits of incorporating CNTs to traditional fiber-reinforced thermoplastic composites, it is important to provide a general overview of the current state-of-the art properties for these conventional composites, including the best-inclass existing commercially available materials. Taking into account the huge amount of data regarding thermoplastic-based materials, data from only the polymer matrices that have been used to date for the development of hierarchical composites will be considered. These include two high-performance polymers, poly(ether ether ketone) (PEEK) and polyimide (PI), an engineering thermoplastic, polyamide-6 (PA-6), and two commodity polymers, polypropylene (PP) and poly(methyl methacrylate) (PMMA). Representative mechanical and thermal property data from these matrices reinforced with CFs and GFs are collected in Table 1 (see Refs. [50-70]). For comprehensive information on the processing and properties of these materials, the reader is referred elsewhere $[4,12,18,71]$.

\section{Processing of hierarchical thermoplastic-based composites}

The most widely used method to manufacture hierarchical composites involves the initial dispersion of the CNTs within the matrix resin through the common approaches developed for binary CNT-reinforced composites (i.e. shear-mixing or ultrasonication) following by infusion of the modified liquid resin or polymer melt into the primary fiber assembly using techniques such as resin transfer molding (RTM) or vacuum-assisted resin transfer molding (VARTM). This approach is simple, scalable and compatible with industrial processes, but it is limited to low CNT loading fractions (around 1 vol.\%). In addition, it leads to a strong increase in the vis- cosity of the matrix and void formation, which may result in incomplete fiber wetting [21], and thus cannot be applied to manufacture highly viscous thermoplastic-based composites. In this case, hot-press processing is generally used to impregnate the fibers with the polymer/CNT mixture $[35,37,45]$. Díez-Pascual et al. $[35,36,39]$ followed this procedure to prepare GF-reinforced poly(ether ether ketone) (PEEK)/SWCNT laminates. Prior to laminate manufacture, PEEK was melt-blended with different types of SWCNTs (neat or wrapped in polyetherethersulfone (PEES) as a compatibilizing agent), and thin films ( $\sim 500 \mu \mathrm{m}$ thick) subsequently prepared in a hot-press utilizing a brass picture frame to control film dimensions (Fig. 1a). The laminates were fabricated by alternatively placing 4 PEEK/SWCNT films within $5 \mathrm{GF}$ fabric plies (Fig. 1b). Consolidation of the material was also undertaken in a hot-press at $380^{\circ} \mathrm{C}$ under high pressure for about $30 \mathrm{~min}$ (Fig. 1c). The resulting laminates had a fiber volume fraction of 0.48 and a void content $<3 \%$. Similar approach was reported by Shen et al. [37] for the manufacture of polyamide-6 (PA-6)/ MWCNT/GF composites. PA-6/MWCNT nanocomposites were initially extruded into films of $\sim 100 \mu \mathrm{m}$ thick; then, 10 plies of GF woven fabric and 11 film layers were alternatively stacked and heated at $240{ }^{\circ} \mathrm{C}$ for $10 \mathrm{~min}$ and subsequently hot-pressed at $800-1000 \mathrm{kPa}$ for $10-20 \mathrm{~min}$ to obtain good quality laminates with a void content $<2 \%$ and a fiber volume fraction of 0.30 .

Another approach consists in the grafting of CNTs onto conventional fibers via chemical vapor deposition (CVD) [42,43], in which the CNTs are grown directly on the fiber surface in the presence of a metal catalyst (i.e. $\mathrm{Ni}$ or $\mathrm{Fe}$ ). The catalyst can be deposited by various methods, including solution impregnation, sputtering, electron beam, thermal evaporation, electrodeposition, etc. The CNT growth is undertaken in a quartz tube reactor by using acetylene $\left(\mathrm{C}_{2} \mathrm{H}_{2}\right)$ as the hydrocarbon source. $\mathrm{A} \mathrm{H}_{2} / \mathrm{Ar}$ mixture is employed as the carrier gas. The reaction is typically performed at 550$750^{\circ} \mathrm{C}$ for $25-60 \mathrm{~min}$, using a 1:300 flow ratio of $\mathrm{C}_{2} \mathrm{H}_{2}$ to carrier gas. Qian et al. reported the preparation of poly(methyl methacrylate) (PMMA) based composites incorporating CNTs grown onto CFs [42] and silica fibers [43] by this procedure. A $10 \mathrm{wt} . \%$ solution of PMMA in 1,4-dioxane was then prepared and cast onto the fibers, and the resulting composite films were vacuum dried to remove the solvent. A similar approach was described Rahmanian et al. [23] who synthesized MWCNTs onto short CFs and GFs via feeding a vaporized solution of benzene and ferrocene into a CVD reactor; the hybrid fibers where then blended with polypropylene (PP) in an internal mixer at $170^{\circ} \mathrm{C}$. This methodology has several advantages, the most important being the feasibility to introduce high loadings of aligned CNTs. However, some disadvantages such as scalability (due to the limitations in growing the CNTs in large volumes), the use of metal catalysts in the growth process, and difficulties when functionalizing CNTs grown on fibers with functional groups that are compatible with the resin were also found. Furthermore, degradation of the fibers due to extreme conditions of the CVD process is also of concern since it could undermine the fiber dependent properties of the composite.

Alternatively, CNTs have been dispersed in the sizing of the fibers, which protects the fiber surface and improves stress transfer at the interface. Following this procedure, Rausch and Mäder [3032] prepared MWCNT-coated GF yarns embedded in a polypropylene (PP) matrix. GF yarns were sized with a $1 \mathrm{wt}$.\% 1-aminopropyltriethoxysilane (APS) aqueous solution and then coated with a film containing 0.5 wt.\% [31,32] or $0.04-0.2$ wt.\% [30] MWCNTs. The coated GFs were embedded in PP by compression molding [31,32] or by simultaneous melt-spinning and co-mingling at a speed of $700 \mathrm{~m} / \mathrm{min}$ [30]. Barber et al. [29] fabricated isotactic polypropylene (iPP)/SWCNT/GF composites also using a technique based on sizing, where SWCNTs were dispersed in a solution of an industrial sizing at a concentration of $0.5 \mathrm{wt}$.\% using an ultrasonic 
Table 1

Mechanical and thermal properties of representative conventional and commercial GF and CF-reinforced thermoplastic composites.

\begin{tabular}{|c|c|c|c|c|c|c|c|c|c|c|c|c|}
\hline Matrix & $\begin{array}{l}\text { Fiber } \\
\text { (wt.\%) }\end{array}$ & $\begin{array}{l}E \\
(\mathrm{GPa})\end{array}$ & $\begin{array}{l}\sigma_{y} \\
(\mathrm{MPa})\end{array}$ & $\begin{array}{l}G \\
\left(\mathrm{~kJ} / \mathrm{m}^{2}\right)\end{array}$ & $\begin{array}{l}G \\
(\mathrm{~J} / \mathrm{m})\end{array}$ & $\begin{array}{l}E_{f} \\
(\mathrm{GPa})\end{array}$ & $\begin{array}{l}\sigma_{f M} \\
(\mathrm{MPa})\end{array}$ & $\begin{array}{l}\text { ILSS } \\
(\mathrm{MPa})\end{array}$ & $\begin{array}{l}\text { HDT } \\
\left({ }^{\circ} \mathrm{C}\right)\end{array}$ & $\begin{array}{l}\lambda \\
\left(\mathrm{W} \mathrm{m}^{-1} \mathrm{~K}^{-1}\right)\end{array}$ & Commercial name & Ref. \\
\hline PEEK & GF (30) & 11.8 & 180 & 8 & & 11.3 & 270 & & 328 & 0.30 & $\begin{array}{l}\text { Victrex } \\
\text { PEEK } 450 \text { GL } 30\end{array}$ & [50] \\
\hline PEEK & $\mathrm{CF}(30)$ & 26.0 & 260 & 6 & & 24.0 & 360 & & 339 & 0.95 & $\begin{array}{l}\text { Victrex } \\
\text { PEEK } 150 \text { CA } 30\end{array}$ & [50] \\
\hline PEEK & GF (30) & 11.4 & 165 & 13 & & 10.7 & 246 & & 315 & 0.29 & $\begin{array}{l}\text { KetaSpire } \\
\text { KT-820 GF } 30\end{array}$ & [51] \\
\hline PEEK & $\mathrm{CF}(30)$ & 22.8 & 217 & 10 & & 20.5 & 311 & & 315 & 0.37 & $\begin{array}{l}\text { KetaSpire } \\
\text { KT-820 CF } 30\end{array}$ & [51] \\
\hline PEEK & CF $(30)$ & 7.7 & 130 & 35 & & & & & & & & [52] \\
\hline PEEK & GF $(30)$ & 6.3 & 90 & 35 & & & & & & & & [52] \\
\hline PEEK $^{2}$ & GF (65) & & & & & $22-29$ & $408-697$ & $32-42$ & & & & [53] \\
\hline PEEK & GF (65) & & 260 & & & & 324 & 51 & & & & [54] \\
\hline PI & GF (30) & 10.7 & 159 & & 120 & 10.3 & 234 & & 316 & & RTP 4205 & [55] \\
\hline PI & CF (30) & 19.9 & 214 & & 85 & 19.3 & 331 & & 316 & & RTP 4285 & [55] \\
\hline PI & $\mathrm{CF}(5)$ & 6.1 & 130 & & 53 & 5.9 & 212 & & 260 & & Stat-Tech PI-05CF & [56] \\
\hline PI & $C F(30)$ & 12.4 & 219 & 21 & & 13.5 & 327 & & & & & [57] \\
\hline PI & GF (30) & 7.5 & 137 & 23 & & 9.2 & 211 & & & & & [57] \\
\hline PI & CF $(30)$ & 3.0 & 114 & & & & & & & & & [58] \\
\hline PA-6 & GF $(30)$ & 10.3 & 203 & 18 & & 8.8 & & & 207 & & Celstran PA6-GF30 & [59] \\
\hline PA-6 & GF (30) & 9.6 & 185 & 13 & & 8.5 & 270 & & 210 & & AKROMID B GF30 & [60] \\
\hline PA-6 & $C F(20)$ & 12.1 & 161 & & 48 & 10.7 & 241 & & 205 & & Stat-Tech NY-20CF & [56] \\
\hline PA-6 & GF $(50)$ & 12.1 & 224 & & 133 & 13.8 & 326 & & & & HMG10 & [61] \\
\hline PA-6 & GF $(50)$ & & 220 & & 266 & & 345 & & & & Verton PF-700-100 & [62] \\
\hline PA-6 & GF (50) & & 234 & & 313 & 11.4 & 349 & & 220 & & & [63] \\
\hline PA-6 & GF (30) & 9.5 & 132 & & 162 & & & & & & & [64] \\
\hline $\mathrm{PP}$ & GF (15) & 5.3 & 110 & 10 & & & & & 140 & & AKROMID A3 GF15 & [60] \\
\hline $\mathrm{PP}$ & GF $(30)$ & 6.4 & 108 & 20 & & 6.0 & 155 & & 150 & & Celstran PP-GF30 & [59] \\
\hline PP & GF $(10)$ & & 41 & & 53 & 2.8 & 55 & & 129 & & HiFill PP GF10 & [65] \\
\hline PP & GF (10) & 3.3 & 48 & & 53 & 2.8 & 72 & & 129 & & RTP PP 10GF & [55] \\
\hline PP & CF $(40)$ & & 65 & & 110 & 8.3 & 131 & & 127 & & HiFill PP CF40 & [65] \\
\hline PP & CF (5) & & 24 & & 67 & & 37 & & & & & [66] \\
\hline PP & GF (5) & 2.3 & 32 & 5 & & & & & & & & [67] \\
\hline PP & GF (5) & 0.9 & 34 & & 18 & 1.4 & 48 & & & & & [68] \\
\hline PMMA & GF $(30)$ & 10.3 & 103 & & 53 & 10.3 & 152 & & 93 & & RTP 1805 & [55] \\
\hline PMMA & CF (30) & 18.6 & 134 & & 59 & 15.9 & 186 & & 132 & & RTP 1885 & [55] \\
\hline PMMA & GF (4) & & & & & 2.5 & 92 & & & & & [69] \\
\hline PMMA & $\mathrm{CF}(20)^{\mathrm{b}}$ & 2.6 & 65 & & & & & & & & & {$[70]$} \\
\hline
\end{tabular}

E: Young's modulus; $\sigma_{y}$ : tensile strength at yield; $G$ : impact strength; $E_{f}$ flexural modulus; $\sigma_{f M}$ : flexural strength; ILSS: interlaminar shear strength; HDT: heat distortion temperature; $\lambda$ : thermal conductivity.

${ }^{\text {a }}$ PEEK yarn.

${ }^{\mathrm{b}}$ Content in vol.\%.

probe. GFs were then submerged into the sizing-SWCNT solution for $10 \mathrm{~min}$, and their surface was further modified by applying a polymer emulsion coating. Subsequently, the GFs were placed between two iPP sheets (thickness $\sim 0.1 \mathrm{~mm}$ ) and hot-pressed at $200^{\circ} \mathrm{C}$ under 1.4 MPa. The main disadvantages of this technique are the poor control of CNT orientation and the potentially weak CNT attachment due to the lack of chemical bonding.

Another potential method to prepare hierarchical composites consists in the deposition of CNTs onto the surface of fabric layers by electrophoretic deposition (EPD) [27]. In this process amine or carboxylic acid functionalized CNTs are dispersed in a liquid medium, and upon application of an electric field they are displaced and deposited onto the fabric. The resulting plies are then alternatively staked with the polymer layers and the material is consolidated by hot-compression. This is a promising approach in terms of practicality, scalability, and cost-effectiveness, although it exhibits similar disadvantages as the fiber sizing methods. Alternatively, negatively charged CNTs prepared via oxidation treatment can be deposited onto positively charged functionalized GFs via electrostatic assembly [28], and the thickness of the adsorbed CNT layer can be tuned by modifying the assembly conditions ( $\mathrm{pH}$, concentration of the CNT solution, etc.). This technique leads to more uniform and compact preforms than other deposition methods that can be easily melt-compounded with the thermoplastic matrix.

\section{Characterization of hierarchical thermoplastic-based composites}

\subsection{Structure and morphology}

The morphological characterization of multiscale CNT-reinforced composites is typically carried out by imaging techniques such as scanning electron microscopy (SEM), which provides information about the orientation and distribution of the nanofillers, and some insight into the interfacial adhesion strength between the polymer and the different reinforcements as well as the wetting of the fibers by the matrix. These factors are known to have strong impact on the final mechanical properties of the composites [37]. Most studies did not report the CNT orientation, although a random arrangement or alignment parallel to the fibers in the direction of the viscous flow of the matrix is the most likely. Ashrafi et al. [36] employed optical microscopy and SEM to examine the surface morphology of non-compatibilized and compatibilized high-performance PEEK/SWCNT (1.0 wt.\%)/GF laminates at the micro- and nano-scale, respectively (Fig. 2a-d). Composites including SWCNT wrapped in PEES were found to be very homogeneous, exhibiting a random and improved nanofiller dispersion within the matrix (Fig. 2a) and very low degree of porosity. The compatibilizing agent induced CNT disentanglement and debundling, and 
(a)
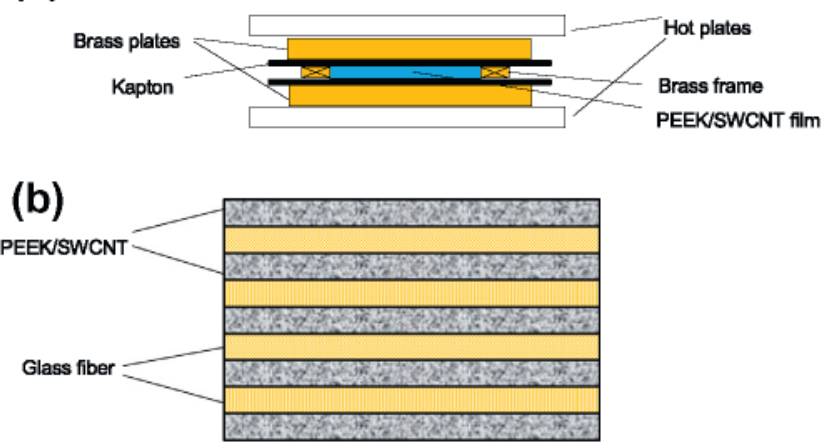

(c)

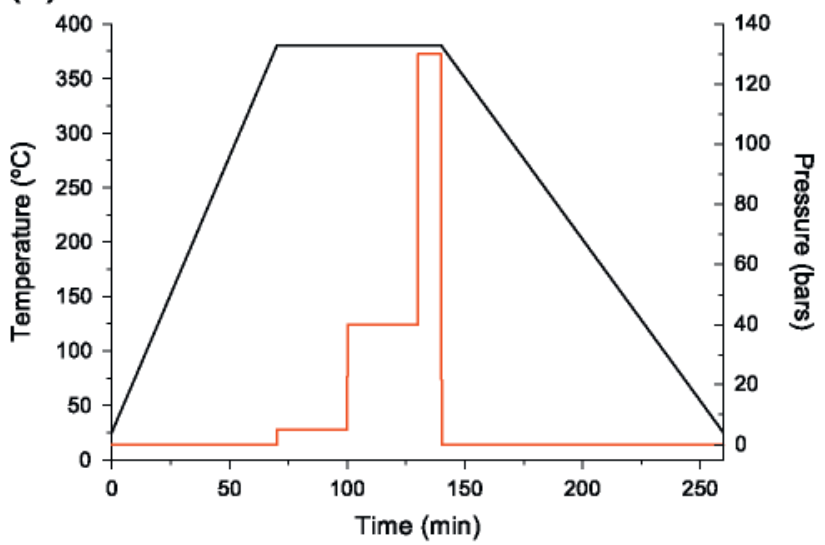

Fig. 1. (a) Schematic representation of the hot-press used for the preparation of the PEEK/SWCNT films. (b) Scheme of the lay-up stacking sequence of the PEEK/ SWCNT/GF hierarchical composites. (c) Consolidation cycle for composite manufacturing. From Ref. [35], copyright 2011, with permission from Elsevier.

the SWCNTs were able to penetrate the fiber tows (Fig. 2b), leading to a good tow impregnation. In contrast, SWCNT agglomerates $(\geqslant 2 \mu \mathrm{m})$ forming a highly entangled interconnected structure were observed in the non-compatibilized composites (Fig. 2c); the aggregates enveloped the fiber tows but did not penetrate into them (Fig. 2d), resulting in poorer GF impregnation and higher void content. In a following study [39], the authors correlated the morphology with the melt-viscosity $(\eta)$ of the composites (Fig. 2e). The addition of SWCNTs to PEEK/GF led to significant rises in $\eta$, by $\sim 5$ and 40 -fold increases at $0.01 \mathrm{~Hz}$ for non-wrapped and wrapped SWCNTs, respectively. Despite the fact that the compatibilized laminates displayed the highest viscosity, which should make difficult the flow of the matrix during the hot-compression process, they showed complete fiber wetting. This striking behavior can be ascribed to the use of acid-functionalized SWCNTs that are suitable to interact with both the GF (through $\mathrm{H}$-bonding) and the matrix (via $\pi-\pi$ stacking). All these interactions, combined with the compatibilization effect overweighed the rise in viscosity, resulting in enhanced GF wetting.

SEM analysis was also applied to characterize the fractured surfaces of PA-6/MWCNT (0.5-4.0 wt.\%)/GF laminates [37]. All the composites displayed good nanofiller dispersion within the matrix, as revealed by transmission electron microscopy (TEM) micrographs that showed individual MWCNTs with an aspect ratio in the range of 100-1000 (Fig. 2f). While some dry fibers were found in the laminate with 4.0 wt.\% MWCNTs (Fig. 2g), composites with lower loadings (0.5, 1.0 and 2.0 wt.\% MWCNTs) displayed complete fiber impregnation. The authors explained this fact based on the different viscosities of the PA-6/CNT nanocomposites used as matrices for the fabrication of the hierarchical composites
(Fig. 2h). Thus, $1.0 \mathrm{wt} . \%$ MWCNTs hardly modified the viscosity of PA-6, whereas the addition of $4.0 \mathrm{wt}$.\% loading led to more than a 10 -fold rise at a frequency of $0.01 \mathrm{~Hz}$. The high viscosity of the PA-6/CNT (4.0 wt.\%) mixture hindered the viscous flow of the matrix during processing, causing uneven and poor GF wetting. In this case raw MWCNTs without any surfactant or modifier were used as nanoreinforcement, which do not interact with the GF nor with the matrix. From the abovementioned studies, it can be drawn that the level of interfacial interaction between the different components of the hierarchical laminates plays a key role on the degree of fiber impregnation, and consequently on the final properties of the material.

Rausch and Mäder [31] studied the topography of MWCNT (0.5 wt.\%)/GF yarns embedded in PP (Fig. 3). Clearly, the GF surface is not uniformly nor completely covered by the CNT-modified film, and some cluster-like structures can be observed (Fig. 3a). To improve the electrical properties of the composites, a more homogenous coating layer with interconnected areas and continuous paths rather than an "island-in-the-sea" topography needs to be developed (see scheme in Fig. 3b), which can be attained through different approaches: by using a coating system with enhanced film forming ability, by increasing the amount of CNTs in the sizing/ coating precursor or by annealing the glass fiber yarns. The authors followed the latter method, and after annealing at $200{ }^{\circ} \mathrm{C}$ for $15 \mathrm{~min}$ the GF surfaces were found to be properly wetted by the molten PP (Fig. 3c). The MWCNTs appeared well dispersed within the PP matrix, resulting in the formation of a network that could be observed by monitoring the sample in charge contrast imaging mode (Fig. 3d). This network can be used as a strain sensor to measure the level of interfacial adhesion between the GFs and the matrix.

Most of the studies on thermoplastic based hierarchical laminates focus on the mechanical properties and exclusively correlate the results with the degree of CNT dispersion. However, since these matrices are generally semicrystalline, their microstructure in terms of degree of crystallinity, crystal size and orientation also influences strongly the mechanical performance. Wide angle Xray scattering (WAXS) experiments can be performed to assess their crystal structure and crystallinity, which depends on the thermal history, the manufacturing process employed and the presence of possible nucleation sites. Fig. 4 compares the room temperature WAXS patterns of compatibilized and non-compatibilized SWCNTreinforced PEEK nanocomposites at $1.0 \mathrm{wt}$ \% loading and the corresponding fiber-reinforced laminates. In all samples the main Bragg reflections were observed at angles of $2 \theta=18.7^{\circ}, 20.6^{\circ}, 22.9^{\circ}$ and $28.8^{\circ}$, assigned to the diffraction of the (110), (111), (200) and (211) crystalline planes, respectively, of the orthorhombic unit cell of PEEK [72]. This indicates that all the composites present the same crystalline structure as that of the neat matrix. In the hierarchical laminates, the peaks are slightly wider and less intense in comparison to PEEK/GF. The crystallite size perpendicular to the (200) diffraction plane, $D_{200}$, can be estimated by applying the Scherrer equation: $D_{200}=K \lambda / \beta \cos \theta$, where $\beta$ is the width at half maximun of the diffraction peak, $K$ the Scherrer factor $(\sim 0.9)$ and $2 \theta$ the Bragg angle. The non-wrapped SWCNTs hardly modify the matrix crystal size in the laminate. In contrast, $D_{200}$ for the multiscale compatibilized composite is around $10 \%$ lower than that of PEEK/GF, indicating that the well-dispersed SWCNT network restricts crystal growth reducing this dimension. The formation of smaller crystals can provide excellent rigidity to the polymer matrix.

\subsection{Thermal properties}

\subsubsection{Crystallization and melting behavior}

The crystallization process is one of the most important variables in the fabrication of thermoplastic-based composites and 

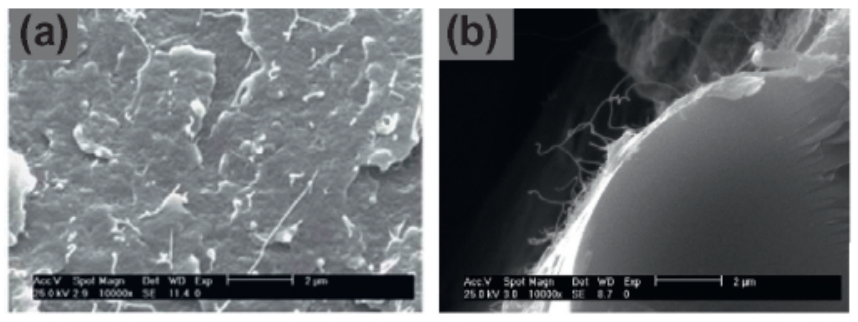

\section{(e)}
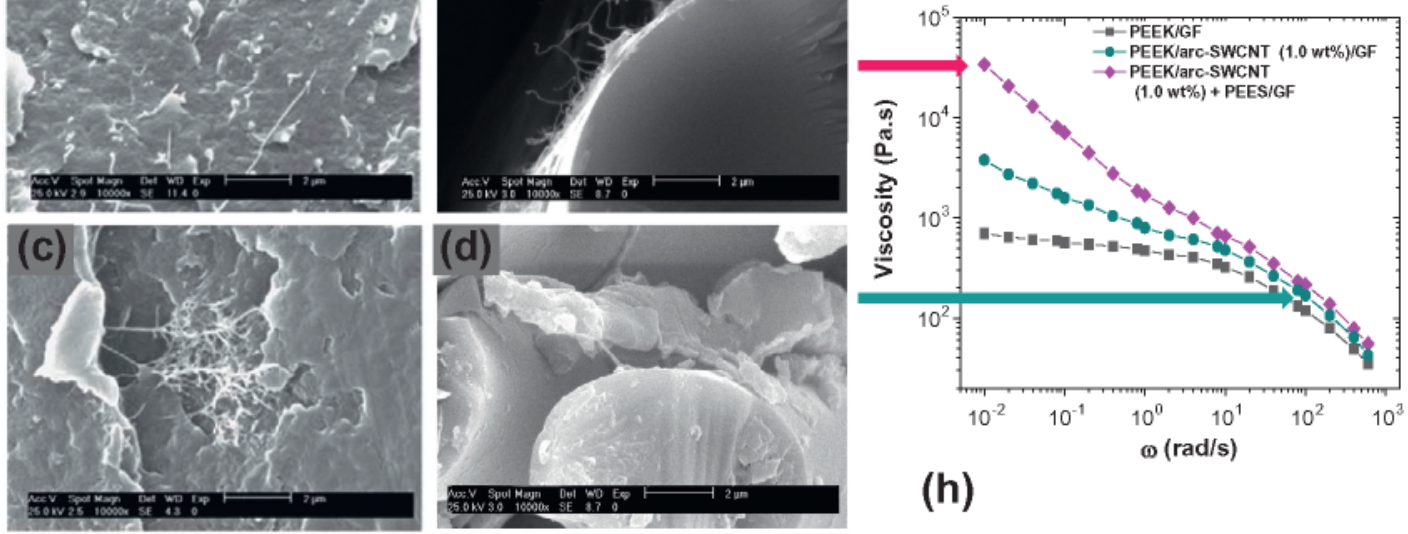

(h)
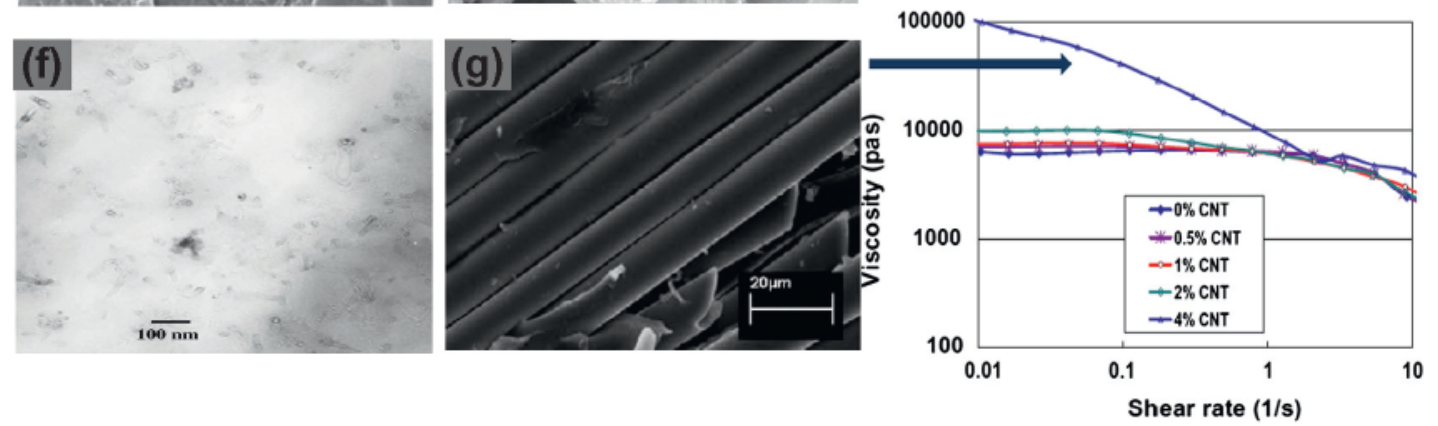

Fig. 2. Scanning electron microscopy (SEM) images obtained from the cross-section of: (a) and (b) PEEK/laser-SWCNT (1.0 wt.\%) + PEES (compatibilizer)/GF; (c) and (d): PEEK/ laser-SWCNT (1.0 wt.\%)/GF. Fig. 2a and 2c were taken from a matrix rich region, while $2 \mathrm{~b}$ and $2 \mathrm{~d}$ correspond to a region within the fiber tows. Adapted from Ref. [36], copyright 2012, with permission from Elsevier. Fig. 2e: Melt-viscosity of compatibilized and non-compatibilized PEEK based hierarchical laminates. Adapted from Ref. [22], copyright 2013, with permission from Elsevier. Fig. 2f: Transmission electron microscopy (TEM) photo of PA-6/MWCNT (4.0 wt.\%) composite. Fig. 2g: SEM image of PA-6/ MWCNT (4.0 wt.\%)/GF laminate. Fig. 2h: Melt-viscosity of PA-6/MWCNT nanocomposites. Adapted from reference [37], copyright 2009, with permission from Elsevier.

plays a key role in the final properties of the material. While it is important to consider the influence of CNTs on the crystallization and melting behavior of the matrix in conventional fiber-reinforced composites, to date very scarce information regarding this subject has been published. Table 2 collects the calorimetric parameters derived from DSC thermograms of hierarchical PEEK/ SWCNT/GF laminates [35]. Composites with 1.0 wt.\% SWCNTs exhibited lower crystallization temperature $\left(T_{c}\right)$ and degree of crystallinity $\left(X_{c}\right)$ than PEEK/GF, and this decrease was more significant in the samples with PEES, an amorphous polymer that perturbs the crystallization of the matrix. However, both parameters remained practically unaffected in the sample incorporating 0.5 wt.\% wrapped SWCNTs. It is well known that there are two factors that control the crystallization of polymeric composite systems [20]; firstly, fillers may have a nucleating effect, which results in higher $T_{c}$ and $X_{c}$, and secondly, fillers can hinder the diffusion and migration of polymer chains, thereby obstructing crystallization. The addition of SWCNTs was reported to be twofold due to the competition of these factors. When $0.5 \mathrm{wt}$.\% SWCNTs was incorporated into PEEK/GF, the nucleating effect probably compensated for restrictions in chain mobility, hence $T_{c}$ and $X_{c}$ hardly changed. However, at higher loadings the formation of a SWCNT network confined the crystal growth leading to a decrease in both parameters. Taking into account that the addition of either GF [35] or SWCNTs [72] to neat PEEK only resulted in a small reduction in $T_{c}$ and $X_{c}$, whereas a moderate decrease was observed by the simultaneous incorporation of the two reinforcements, the authors concluded that there was a synergistic effect of both micro- and nanofillers on inhibiting polymer crystallization. Further, it was reported that the effect of confinement of the polymer chains was more pronounced in the presence of a compatibilizing agent. While the wrapped nanofillers are better dispersed within the matrix, which would accelerate the nucleation process, they can interact strongly with the polymer, resulting in more hindrance to the diffusion of the polymer chains. Overall, the crystallization process is slowed in comparison with composites that include non-wrapped SWCNTs. With regard to the influence of the nanotube type, it was found that laminates with SWCNTs synthesized by the arc-discharge method displayed slightly higher crystallinity than those reinforced with laser-grown SWCNTs, and this was attributed to their higher degree of debundling [35]. One the other hand, only subtle changes were detected in the melting temperature or melting enthalpy upon addition of SWCNTs. The glass transition temperature $\left(T_{g}\right)$ of SWCNT-reinforced laminates (Table 2) is higher than that of PEEK/GF, the increment being stronger for the compatibilized composites, particularly those with laser-grown SWCNTs. This parameter can be more accurately determined by dynamic mechanical analysis (DMA) measurements, as discussed in a following section.

Madër et al. [30] studied the crystallization behavior of PP/ MWCNT (0.04-0.2 wt.\%)/GF hybrid yarns prepared by dispersing the MWCNTs in the fiber sizing. Contrary to the aforementioned results found for SWCNT-reinforced PEEK/GF laminates, they reported an increase in the crystallization rate of the PP matrix in the presence of MWCNTs where the onset of crystallization and the point of maximum heat flow were shifted to shorter times. However, the MWCNT content hardly affected the crystallization kinetics, suggesting that a saturation of the nucleation density had already been reached at the low weight fractions employed. An increase in the crystallization enthalpy was also detected 

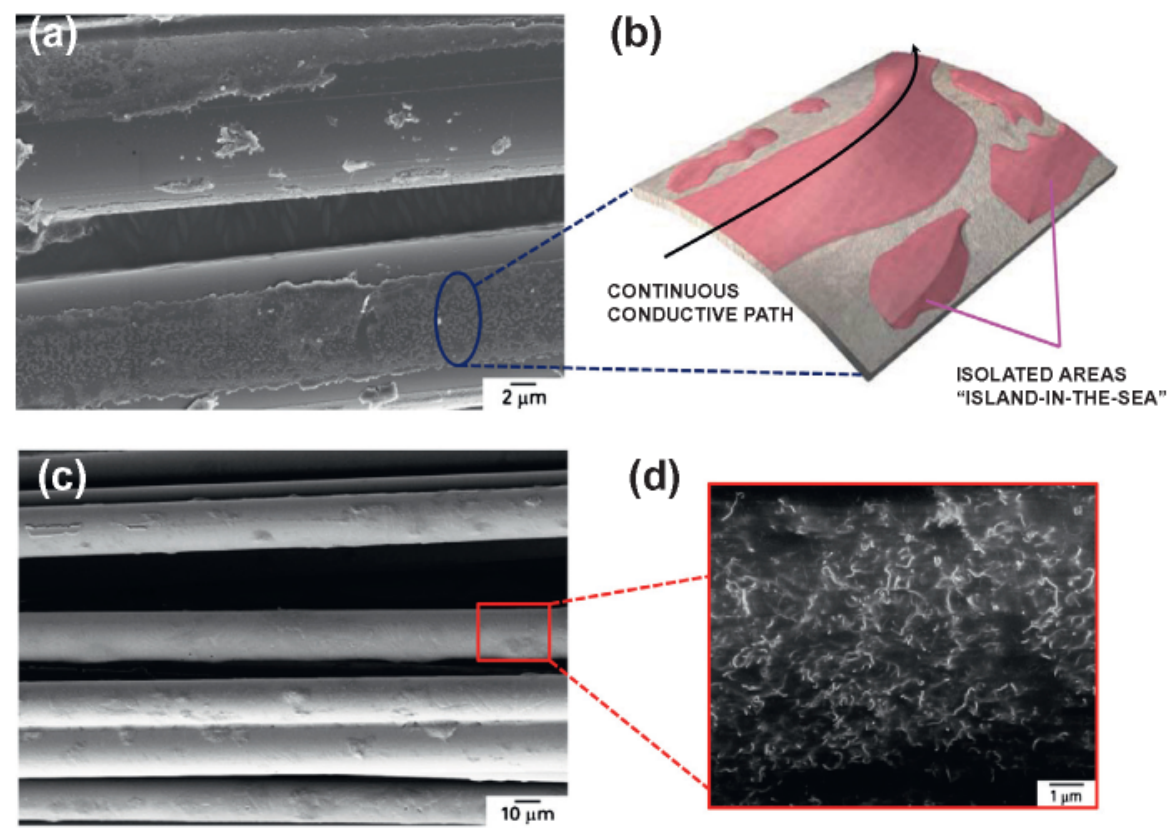

Fig. 3. (a) Typical SEM image from the surface of MWCNT ( 0.5 wt.\%)/GF yarns embedded in a PP matrix. (b) Schematic representation of the GF surface coated by the CNT modified film. (c) GF surfaces after annealing at $200^{\circ} \mathrm{C}$ for $15 \mathrm{~min}$. (d) High magnification charge contrast micrograph of the CNT coating onto the GF after annealing. Adapted from Ref. [31], copyright 2010, with permission from Elsevier.

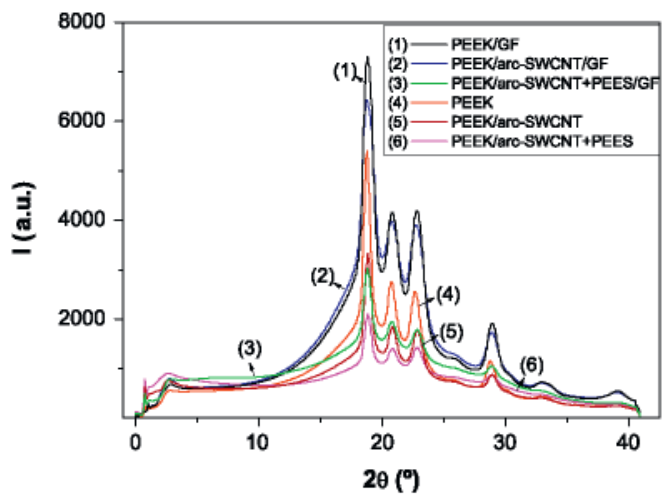

Fig. 4. Wide angle X-ray diffraction patterns (WAXS) of PEEK/arc-SWCNT (1.0 wt.\%) binary nanocomposites and PEEK/arc-SWCNT $(1.0 \mathrm{wt} . \%) / \mathrm{GF}$ laminates with and without PEES as a compatibilizer. The amount of PEES in the compatibilized samples was $\sim 0.1$ wt.\%.

indicating a change in the composite morphology. The MWCNTs acted as heterogeneous nucleation centers on the fiber surface, impeding the lateral growth of crystallites resulting in a transcrys- talline layer around the GFs. This transcrystalline layer was found to be specific for each fiber/sizing/matrix combination.

\subsubsection{Thermal conductivity}

Composites with good thermal conductivity $(\lambda)$ have a great number of potential applications such as printed circuit boards, connectors, thermal interface materials and heat sinks. A few research groups [35-37] have investigated the influence of CNTs on the thermal conductivity of conventional fiber-reinforced thermoplastic composites. Phonon transport in these materials is in the form of diffusion, and since CNTs exhibit ballistic transport properties, the dispersion of CNTs into the matrix is expected to significantly enhance phonon diffusion, thereby improving $\lambda$. Table 3 collects room temperature $\lambda$ values for CNT-based hierarchical PEEK [35] and PA-6 [37] composites manufactured by extrusion and hot-compression. For the sake of comparison, data of the corresponding binary thermoplastic/CNT nanocomposites $[37,73]$ are also included. Regarding the high-performance laminates, the increments in $\lambda$ are in general slightly smaller than those reported for PEEK/SWCNT nanocomposites [73], albeit both families of composites display similar trends. Thus, the thermal conductivity of PEEK/GF was found to be $\sim 0.22 \mathrm{~W} \mathrm{~m}^{-1} \mathrm{~K}^{-1}$, very close to that of the pure resin. The addition of $1.0 \mathrm{wt} . \%$ non-wrapped arc and

Table 2

DSC and TGA thermal parameters for CNT-reinforced PEEK/GF hierarchical composites. Adapted from Ref. [35].

\begin{tabular}{|c|c|c|c|c|c|c|c|}
\hline CNT (wt.\%) & $T_{c}\left({ }^{\circ} \mathrm{C}\right)$ & $X_{c}(\%)$ & $T_{m}\left({ }^{\circ} \mathrm{C}\right)$ & $T_{g}\left({ }^{\circ} \mathrm{C}\right)$ & $T_{i}\left({ }^{\circ} \mathrm{C}\right)^{\mathrm{a}}$ & $T_{\max 1}\left({ }^{\circ} \mathrm{C}\right)^{\mathrm{a}}$ & $T_{\max 2}\left({ }^{\circ} \mathrm{C}\right)^{\mathrm{a}}$ \\
\hline- & 304.2 & 39.4 & 342.2 & 156.1 & 516.2 & 546.6 & 602.3 \\
\hline Arc SWCNTs (1.0) & 300.1 & 37.6 & 341.7 & 160.8 & 523.4 & 553.5 & 611.4 \\
\hline Laser SWCNTs (1.0) & 298.7 & 38.4 & 342.6 & 166.7 & 525.2 & 558.9 & 623.8 \\
\hline PEES-wrapped laser SWCNTs (0.5) & 303.5 & 40.5 & 341.5 & 164.8 & 518.7 & 555.6 & 618.3 \\
\hline PEES-wrapped Laser SWCNTs (1.0) & 296.6 & 36.6 & 339.8 & 178.0 & 546.9 & 568.9 & 640.0 \\
\hline PEES-wrapped arc SWCNTs (1.0) & 294.8 & 35.3 & 340.4 & 172.8 & 550.4 & 577.2 & 642.5 \\
\hline
\end{tabular}

$T_{\mathrm{c}}$ and $T_{m}$ : crystallization and melting temperatures, respectively. $X_{\mathrm{c}}$ : degree of crystallinity. $T_{\mathrm{g}}:$ glass transition temperature obtained from the heating thermograms. $T_{i}$ : initial degradation temperature obtained at $2 \%$ weight loss. $T_{\max }$ : maximum degradation rate temperature; the subscripts 1 and 2 refer to the first and second degradation stages, respectively.

a Data obtained under air atmosphere. 
Table 3

Improvements in room temperature thermal conductivity $(\lambda)$ of CNT-based hierarchical thermoplastic composites manufactured by extrusion and hot-compression. For comparative purposes, data of the corresponding binary thermoplastic/CNT nanocomposites are also included.

\begin{tabular}{|c|c|c|c|c|c|}
\hline Matrix & Fiber (wt.\%) & CNT (wt.\%) & $\lambda\left(\mathrm{W} \mathrm{m}^{-1} \mathrm{~K}^{-1}\right)$ & $\lambda$ increment $^{\mathrm{a}}(\%)$ & Ref. \\
\hline PEEK & - & Arc SWCNTs $(1.0)$ & 0.287 & 30.4 & [73] \\
\hline PEEK & GF (64) & Arc SWCNTs (1.0) & 0.263 & 19.5 & [35] \\
\hline PEEK & - & Laser SWCNTs (1.0) & 0.303 & 37.7 & [73] \\
\hline PEEK & GF (64) & Laser SWCNTs (1.0) & 0.340 & 54.5 & [35] \\
\hline PEEK & - & PEES-wrapped laser SWCNTs (0.5) & 0.375 & 70.5 & [73] \\
\hline PEEK & GF (64) & PEES-wrapped laser SWCNTs (0.5) & 0.272 & 23.6 & [35] \\
\hline PEEK & - & PEES-wrapped laser SWCNTs (1.0) & 0.496 & 125.2 & {$[73]$} \\
\hline PEEK & GF $(64)$ & PEES-wrapped laser SWCNTs (1.0) & 0.424 & 92.7 & [35] \\
\hline PEEK & - & PEES-wrapped arc SWCNTs (1.0) & 0.460 & 109.1 & [73] \\
\hline PEEK & GF (64) & PEES-wrapped arc SWCNTs (1.0) & 0.293 & 33.2 & [35] \\
\hline PA-6 & - & MWCNTs $(0.5)$ & 0.150 & 50.0 & [37] \\
\hline PA-6 & GF (49) & MWCNTs (0.5) & 0.048 & 17.1 & [37] \\
\hline PA-6 & - & MWCNTs (1.0) & 0.190 & 90.0 & [37] \\
\hline PA-6 & GF (49) & MWCNTs (1.0) & 0.049 & 19.5 & [37] \\
\hline PA-6 & - & MWCNTs (2.0) & 0.220 & 120.0 & [37] \\
\hline PA-6 & GF (49) & MWCNTs (2.0) & 0.053 & 29.3 & [37] \\
\hline PA-6 & - & MWCNTs (4.0) & 0.280 & 180.0 & [37] \\
\hline PA-6 & GF (49) & MWCNTs (4.0) & 0.058 & 41.5 & [37] \\
\hline
\end{tabular}

${ }^{a}$ Over values reported for GF-reinforced thermoplastics or neat polymers in the case of binary nanocomposites. Neat resin conductivities: $\lambda_{\mathrm{PEEK}}=0.22 \mathrm{~W} \mathrm{~m}^{-1} \mathrm{~K}^{-1}[73$, $\lambda_{\text {PA-6 }}=0.10 \mathrm{~W} \mathrm{~m}^{-1} \mathrm{~K}^{-1}[37]$.

laser-grown SWCNTs increased this value by about $20 \%$ and $55 \%$, respectively, whilst for the composites with the same SWCNT content wrapped in PEES the increments were $33 \%$ and $93 \%$. This indicates that the thermal conductivity is sensitive to the attributes of the nanofiller (aspect ratio, presence of defects and content in metal impurities) as well as to the presence of the compatibilizer that influences the degree of dispersion. The wrapping in PEES hinders the direct contact between nanotubes, which should lower the thermal conductivity. However, the enhanced SWCNT dispersion compensates for this effect, hence compatibilized samples exhibit higher values than the non-compatibilized ones. $\lambda$ was reported to rise with increasing SWCNT content, to around $50 \%$ enhancement when the concentration was doubled. With regard to the SWCNT type, it was found that laminates incorporating laser-grown SWCNTs exhibited higher conductivity than acid-treated arc-SWCNTs, ascribed to their higher quality (few defects, high crystallinity).

Paradoxically, the $\lambda$ enhancements reported for laminates based on the engineering thermoplastic PA-6 were significantly lower than those found for PA-6/CNT nanocomposites [37]. The differences could be rationalized as follows: Firstly, the laminates display a certain amount of voids that are known to significantly limit the heat transfer ( $\lambda$ of air is $\sim 0.024 \mathrm{~W} \mathrm{~m}^{-1} \mathrm{~K}^{-1}$ ). Secondly, since the laminates are composed of 10 plies of GF and 11 layers of the extruded PA-6/CNT films, the weight percentage of CNTs in the laminates is indeed about half of that in the nanocomposites. Thirdly, during laminate manufacture the orientation of the CNTs and their state of dispersion might have changed from those in the nanocomposites, and these factors strongly influence the thermal conductivity. Nevertheless, for both types of composites, $\lambda$ increased progressively upon addition of increasing amounts of MWCNTs. Thus, the conductivity of the PA-6/GF laminate was reported to be $0.041 \mathrm{~W} \mathrm{~m}^{-1} \mathrm{~K}^{-1}$, and increased up to 0.058 at $4.0 \mathrm{wt}$ \% loading ( $42 \%$ increment). Analogous thermal conductivity improvement behavior has been reported for hierarchical thermoset-based composites incorporating CNTs. Wang et al. [74] reported $\lambda$ improvements of $67 \%$ and $150 \%$ upon addition of 1.0 and $3.0 \mathrm{wt} . \%$ MWCNTs, respectively, to polyester/vinyl ester resin/GF composites. Assael and co-workers [75], studying epoxy/ MWCNT/GF composites found a maximum enhancement in $\lambda$ of $60 \%$ at 1.2 wt.\% loading, and Kim et al. [76] reported the same improvement for phenolic resin/CF composites upon addition of 7.0 wt.\% highly crystalline MWCNTs. They demonstrated that heat treated MWCNTs homogeneously dispersed within the matrix acted as an effective thermal bridge between adjacent carbon fibers embedded in the composite, whereas pristine MWCNTs resulted in reduced $\lambda$ values due to their larger amount of defects. For a CNT concentration of about $1 \mathrm{wt} . \%$, the highest $\lambda$ increment among hierarchical composites has been reported for PEEK/PEES wrapped-laser SWCNTs/GF, attesting to the efficiency of this compatibilizer for improving nanotube dispersion.

The thermal conductivity of multiscale CNT-reinforced composites can be predicted by two-phase modeling. Firstly, $\lambda$ of polymer/ CNT composites can be estimated following the modified rule of mixtures: $\lambda_{c}=\eta_{l}^{2} \lambda_{f} V_{f}+\lambda_{m}\left(1-V_{f}\right)$, where $\lambda_{f}$ and $\lambda_{m}$ are the thermal conductivity of the filler and the matrix, $V_{f}$ the filler volume fraction and $\eta_{l}$ the length efficiency factor that accounts for the CNT waviness. Dispersion of CNTs into the polymer results in a new matrix phase with improved properties, the fibers can now be regarded as the filler phase, and the rule of mixtures can be subsequently used to calculate $\lambda$ for the laminates. This approach has been used to predict the thermal conductivity of PEEK/ SWCNT/GF [35]. Theoretical values were found to be significantly higher than the experimental data except for compatibilized composites reinforced with laser-grown SWCNTs, where deviations with respect to the predictions were about $22 \%$ and $25 \%$ for 0.5 and $1.0 \mathrm{wt}$ \% loadings, respectively. Discrepancies between the theoretical and experimental values can be attributed to the low thermal conductance of the CNT-polymer interface and the high interfacial thermal resistance between SWCNTs that considerably limits heat transfer. To fully exploit the potential of CNT fillers in the fabrication of highly thermal conductive composites, new approaches for reducing the nanotube-matrix thermal interfacial resistance need to be developed, like the formation of covalent bonds between functionalized CNTs and polymer derivatives of the thermoplastic matrix.

\subsubsection{Thermal stability and flammability}

The thermal stability of polymer composites not only depends on the intrinsic stability of each component and their relative composition, but also on morphological factors, such as the size, degree of dispersion of the filler and level of interfacial adhesion with the matrix. To evaluate the effect of these parameters on the stability of hierarchical CNT-reinforced composites, TGA experiments are typically carried out under oxidative and/or inert conditions. The characteristic degradation temperatures for PEEK/SWCNT/GF lam- 
inates in air atmosphere are collected in Table 2. All the multiscale composites displayed two degradation steps [35], similar to PEEK and PEEK/GF, the first related to the scission of the polymeric chains and the second to the degradation of aromatic structures. PEEK/GF starts to degrade $\left(T_{i}\right)$ around $516^{\circ} \mathrm{C}$ and shows maximum rates of weight loss $\left(T_{\max 1}\right.$ and $\left.T_{\max 2}\right)$ at 547 and $602^{\circ} \mathrm{C}$, respectively. The incorporation of SWCNTs, particularly those wrapped in PEES, led to a significant rise in the degradation temperatures of the matrix. Thus, for the compatibilized laminate with $1.0 \mathrm{wt} . \%$ laser SWCNTs, $T_{i}, T_{\max 1}$ and $T_{\max 2}$ increased by $\sim 34,30$ and $40^{\circ} \mathrm{C}$, respectively, in comparison with PEEK/GF, whereas for the noncompatibilized counterpart the increments were only 9, 12 and $22^{\circ} \mathrm{C}$. The authors attributed these improvements to the barrier effect of the SWCNTs, which effectively hinder the diffusion of degradation products from the bulk of the polymer to the gas phase, hence slowing the decomposition process. The compatibilizer enhances the dispersion of the nanofillers and their adhesion with the polymer matrix increasing the barrier effect that is reflected in higher degradation temperatures. For the same SWCNT content, $T_{i}, T_{\max 1}$ and $T_{\max 2}$ of laminates reinforced with laser SWCNTs were on average 2,6 and $10^{\circ} \mathrm{C}$ higher than those including arc-SWCNTs, which was attributed to their higher thermal conductivity that facilitates heat dissipation within the composite. The thermal stability enhancements found in these multiscale laminates are higher than those reported for binary PEEK/SWCNT (1.0 wt.\%) nanocomposites [72], where the increments in $T_{i}$ and $\mathrm{T}_{\max }$ were only around 5 and $8{ }^{\circ} \mathrm{C}$, respectively. These significant increments were ascribed to a synergistic stabilization effect arising from the presence of both fillers [35], since the GFs also delay the degradation process of the matrix.

Analogously, improvements in thermal stability have been reported when MWCNTs were incorporated into PA-6/GF [37]. Since the thermal degradation of the matrix initiates with chain cleavage and radical formation, the MWCNTs acted as radical scavengers, delaying the onset of degradation. Interestingly, the increments in the degradation temperatures of PA-6 based laminates are considerably smaller than those found for PEEK-based composites, which is consistent with the trends found for the thermal conductivity data, as discussed previously (Table 3 ). Furthermore, the raw MWCNTs cannot interact with the PA-6 matrix, while the SWCNTs can interact with PEEK via $\pi-\pi$ stacking, resulting in stronger interfacial adhesion, hence more effective barrier effect. On the other hand, PA-6/MWCNT/GF composites showed enhanced fire resistance, as demonstrated from the heat release rate curves obtained from cone calorimetry test experiments (Fig. 5). Both the ignition time and the time of peak heat release rate were found to rise gradually with increasing MWCNT content. The ignition time of the laminate with 4 wt.\% MWCNTs was about $31 \%$ longer than that of binary PA-6/GF, and its peak heat release rate (HRR) was also delayed significantly, by about $118 \%$. These improvements were attributed to the formation of a conductive network that dissipates the heat quickly through the bulk of the composite, taking longer for the surface temperature of the sample to reach the ignition point. This is the first cone test study on this type of laminates reported in the literature.

Recently, natural fiber-reinforced composites such as polylactic acid (PLA) filled with hemp, flax or kenaf have attracted a lot of attention for transport applications as a result of their lighter weight, improved fuel efficiency and reduced emissions in comparison to conventional fiber reinforced plastics [77]. However, to implement these materials within the industrial sector it is necessary to improve their flame retardancy. In this context, Hapuarachchi et al. [45] incorporated MWCNTs and sepiolite nanoclays into PLA/hemp to develop fully bio-based hybrid composites with enhanced flame performance. Cone calorimetry results (Fig. 6) revealed an initial quick rise in HRR for all the (a)
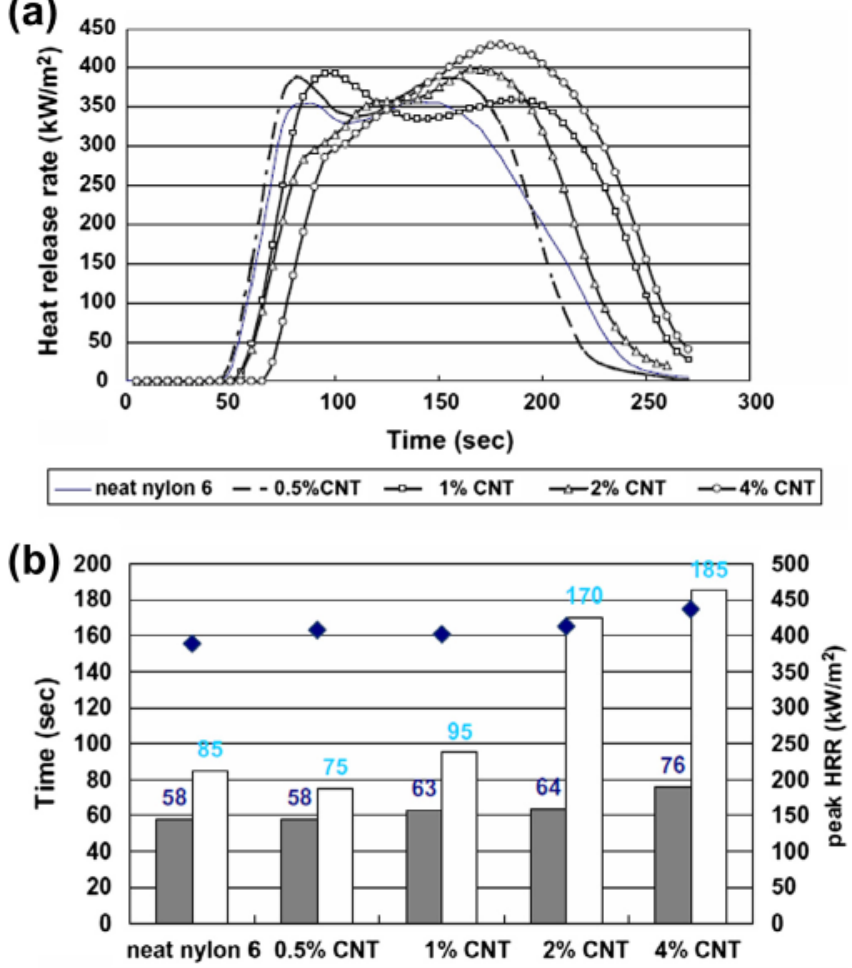

$\square$ Time to Ignition (s) $\square$ Time of peak HRR (s) $\bullet$ peak HRR (kW/m²)

Fig. 5. Cone calorimetry tests results for PA-6/MWCNT/GF laminates: (a): Heat release rate curves; (b) ignition time, peak heat release time and value. From Ref. [37], copyright 2009, with permission from Elsevier.

hemp-reinforced composites, attributed to the faster decomposition of the resin surface layer. The HRR diminished with increasing time, since the char protection reduced the amount of polymer material available for combustion. At around $400 \mathrm{~s}$ the HRR increased again, ascribed to severe lofting and delamination during flaming combustion (Fig. 6a and c). Nevertheless, the hemp/ternary nanocomposite displayed a considerably smaller second peak HRR compared to PLA/hemp composite. It was suggested that the CNTs acted as a sealing agent to create a network with the clay layers, forming a much tighter char than clay alone. The formation of more char reduced the amount of volatile gases escaping from the degrading polymer and hindered the oxygen ingress, thus decreasing the HRR.

\subsubsection{Heat distortion temperature}

The heat distortion temperature (HDT) is the temperature at which a polymeric sample deforms under a specified load and is used in many aspects of material design, engineering and manufacture. To date, very scarce information related to the HDT of continuous fiber-reinforced laminates has been published [78]. Although in theory the HDT is expected to increase on the addition of nanoparticles into the matrix [79], for a PA-6/GF (49 wt.\%) laminate the HDT value of $216^{\circ} \mathrm{C}$ remained virtually unchanged upon addition of $0.5-4.0 \mathrm{wt}$.\% MWCNT loading [37]. In contrast, the incorporation of $3.0 \mathrm{wt} . \%$ nanoclay into PA-6/GF (10-30 wt.\%) laminates provided temperature increases in the HDT of the matrix in the range of 11$18 \%$, pointing towards a synergistic effect [78]. The different behavior between the two types of systems was ascribed to differences in the GF to nanofiller ratio. In the case of the MWCNT reinforced laminates this ratio was very high, thus the GFs played a dominating role in the HDT properties, and no cooperative effects between both fillers could be detected. Consequently, any subtle 
(a)
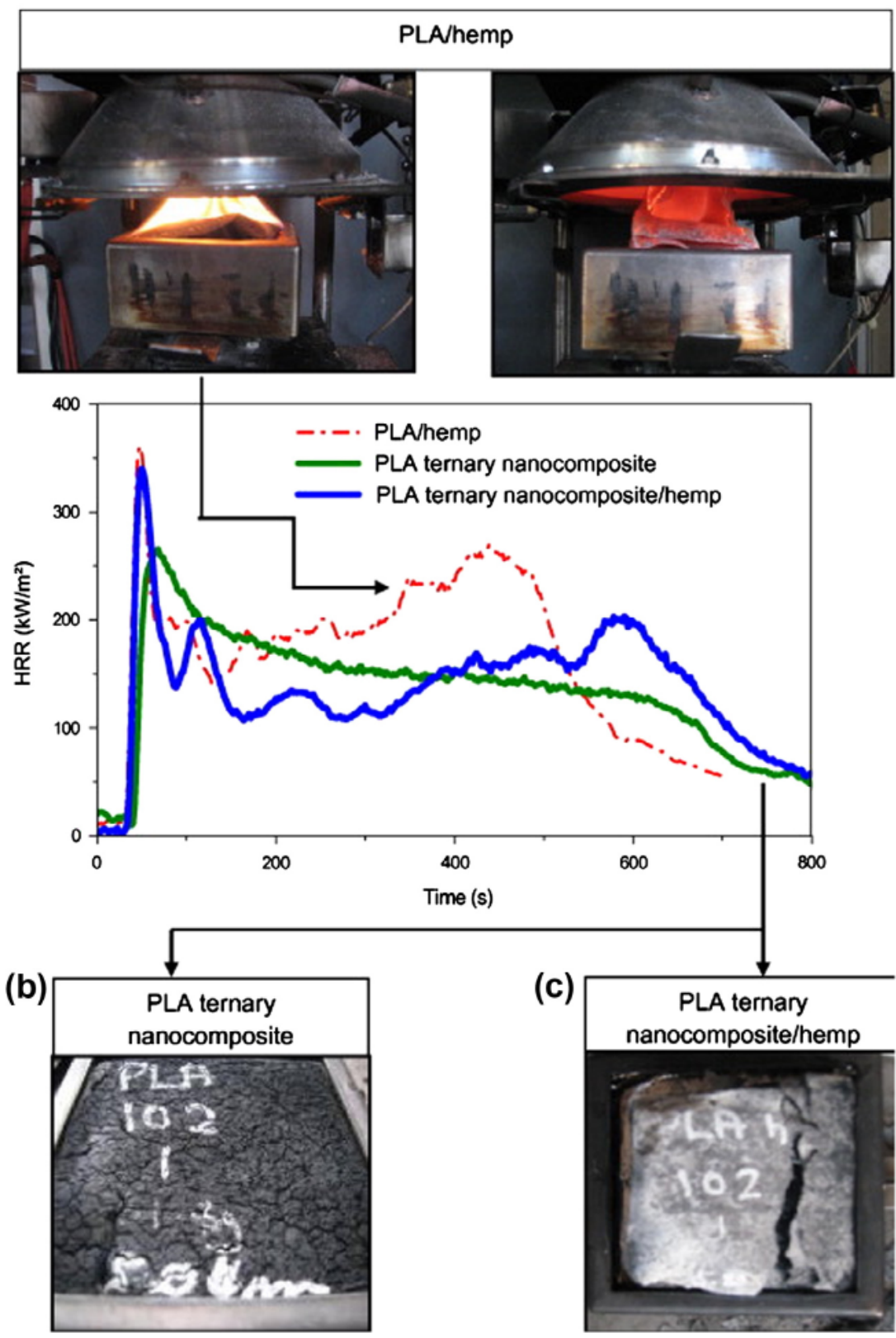

Fig. 6. Heat release rate profiles obtained from cone calorimetry and photographs of: (a) PLA/hemp composite during testing; (b) PLA/MWCNT/sepiolite nanoclay post testing and (c) PLA/hemp/ MWCNT/sepiolite nanoclay post testing. From Ref. [45], copyright 2010, with permission from Elsevier.

increases in the HDT of the matrix provoked by the incorporation of a low percentage of MWCNTs were not readily reflected in the HDT values of the laminates. Further increasing MWCNT loading would probably result in an increase in the HDT values, although processing of such laminates may become an issue due to their associated high viscosity.

$\mathrm{Li}$ and Bai [46] investigated the HDT of CF-reinforced polyimide (PI) composites incorporating pristine or polyethylene-polyamine surface treated CNTs. The HDT of PI/CF (15 wt.\%) increased from $\sim 115$ up to 125 and $140{ }^{\circ} \mathrm{C}$ upon incorporation of 1.0 wt.\% unmodified or surface modified CNTs, respectively. The addition of polymer treated CNTs on the CF surface provoked higher residual stresses on the fibers, and thus increased the fiber-matrix interface bonding, resulting in a strong HDT improvement $(\sim 22 \%)$.

\subsection{Dynamic mechanical properties}

Very little information regarding the mechanical properties of hierarchical composites as a function of frequency and/or temperature is available. Dynamic mechanical tests (DMA) provide information on the composite stiffness, the transitions and relaxation processes of the resin as well as the fiber-matrix and CNT-matrix interfacial adhesion. Recently, the temperature dependence of the storage modulus $\left(E^{\prime}\right)$ of PEEK/SWCNT/GF laminates was investigated [35] (Fig. 7), and a substantial drop was encountered over the $150-200^{\circ} \mathrm{C}$ range, an interval that corresponds to the glass transition of the composites. At room temperature the incorporation of 1.0 wt.\% non-wrapped arc- and laser-SWCNTs to PEEK/GF led to increases in $E^{\prime}$ of $5 \%$ and $8 \%$, respectively, whereas the same amount of SWCNTs dispersed in PEES raised the modulus by 


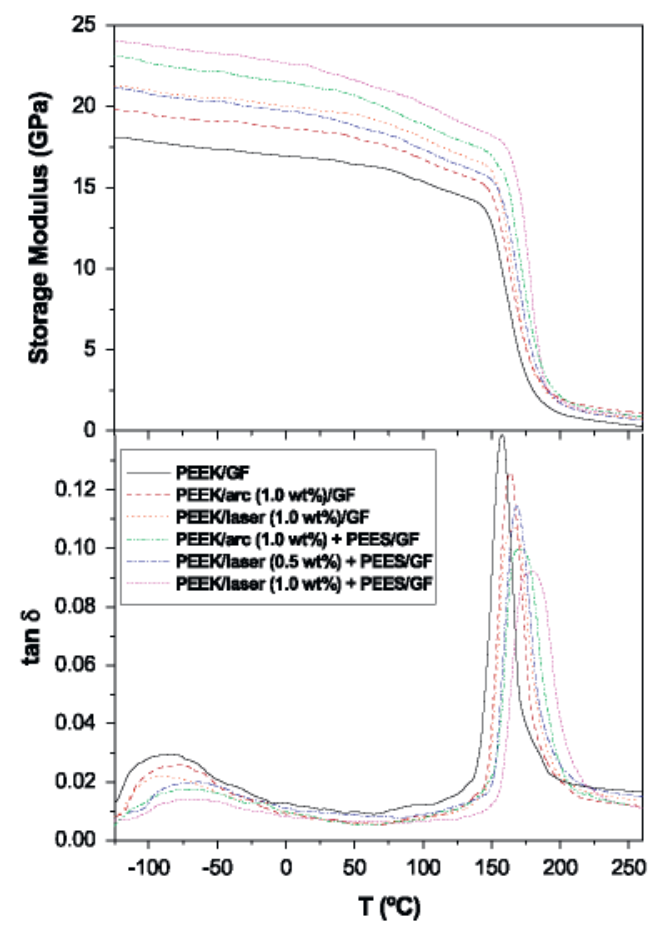

Fig. 7. Storage modulus $\mathrm{E}^{\prime}$ and $\tan \delta$ as a function of temperature, at a frequency of $1 \mathrm{~Hz}$, for PEEK/SWCNT/GF laminates. Adapted from Ref. [35], copyright 2011, with permission from Elsevier.

approximately $18 \%$ and $21 \%$. Similar trends were found over the whole temperature range tested, albeit the relative increment in modulus increased with temperature indicating that the stiffening effect is more pronounced above the softening point of the matrix. The authors attributed the improved behavior of the compatibilized composites to a more uniform SWCNT dispersion and stronger nanotube-PEEK interfacial adhesion enabling more efficient stress transfer. The non-compatibilized samples contained larger SWCNT bundles that were unable to penetrate the fiber tows, leading to inferior fiber impregnation. On the other hand, enhanced modulus was reported for laminates incorporating laser-grown SWCNTs in comparison to those with arc-purified SWCNTs, which was explained considering that the acid treatment could have shortened the tubes and induced sidewall defects, thus reducing their reinforcing efficiency. As expected, $E^{\prime}$ increased with the SWCNT content albeit following a non-linear trend where composites incorporating $1.0 \mathrm{wt}$ \% loading had $\sim 10 \%$ higher modulus than those with 0.5 wt.\%.

Interestingly, a stronger enhancement in $E^{\prime}$ of $\sim 30 \%$ at room temperature has been reported for PA-6/MWCNT (0.18 wt.\%)/GF laminate prepared by electrostatic assembly [28]. The unprecedented improvement attained with such a small amount of MWCNTs results from their interconnecting effect between the fibers and the matrix. Thus, the layer of oxidized MWCNTs adsorbed onto the GFs forms a porous and interconnected structure that can be easily interpenetrated by the polymer, thus improving fibermatrix interfacial adhesion. This novel strategy can solve conventional problems associated with incomplete fiber wetting that limits the property improvements. On the other hand, the reinforcing effect of the MWCNTs was more significant at low temperatures $\left(<60^{\circ} \mathrm{C}\right)$, and became negligible above $120^{\circ} \mathrm{C}$, in agreement with the behavior found for PEEK based laminates.

Accurate information about the transition temperatures of the matrix can be obtained from the plot of $\tan \delta$ (ratio of the loss to storage modulus, a measure of the damping within the system) as a function of temperature. In the case of PEEK based laminates, two relaxation peaks are detected (Fig. 7): the maximum at lower temperatures, $\beta$ relaxation, associated with local motions of the ketone groups, and the most intense peak, $\alpha$ relaxation, related to the $T_{g}$ [35]. The incorporation of SWCNTs decreases the free volume and restricts the mobility of the PEEK chains, which is reflected in higher $T_{g}$ values. The largest increment of $\sim 20^{\circ} \mathrm{C}$ in relation to that of PEEK/GF was found when 1.0 wt.\% laser-grown SWCNTs dispersed in PEES were added. Nevertheless, the incorporation of the same amount of SWCNTs to neat PEEK only increased this temperature by $14^{\circ} \mathrm{C}[73]$. The significant $T_{g}$ enhancement found in the compatibilized multiscale composites was ascribed to the high $T_{g}$ of PEES combined with the improved adhesion between the matrix and nanofiller phases and a joint effect between the micro- and nano-scale fillers on restricting the expansion of the polymer chains, in agreement with the behavior reported for other hierarchical laminates $[34,80]$. Warrier et al. [33] compared the $T_{g}$ of epoxy/GF reinforced with 0.5 wt.\% MWCNTs dispersed either in the fiber sizing or in the matrix. Both composite types showed enhanced values in comparison to the reference without CNTs, and the highest increment of $\sim 12{ }^{\circ} \mathrm{C}$ in $T_{g}$ was attained by incorporating the nanotubes in the sizing. This was ascribed to improved binding of the polymer molecules to the fiber surface. In contrast, the $T_{g}$ of PA-6/GF increased only marginally (by about $3{ }^{\circ} \mathrm{C}$ ) upon incorporation of $0.18 \mathrm{wt}$ \% MWCNTs [28], despite the fact that morphological analysis and $\mathrm{E}^{\prime}$ data suggested an enhanced fibermatrix adhesion in the presence of the nanofillers. It is probable that larger amounts of MWCNTs are required to effectively suppress the mobility of the PA- 6 segments.

The damping in the transition region measures the amount of energy used to deform the material that is directly dissipated into heat. The height of the $\tan \delta$ peak generally decreases in the presence of CNTs indicating a reduction in the mechanical loss to overcome friction between polymer segments. For PEEK/SWCNT/GF laminates [35] this drop was more pronounced in the compatibilized samples, reflecting a more effective immobilization of the polymer chains induced by the SWCNTs dispersed in PEES. Further, this reduction was greater than that found for binary PEEK/SWCNT nanocomposites incorporating the same compatibilizing agent [73], arising from the combined effect of both reinforcements. Moreover, a broadening of the $\tan \delta$ peak was observed that can be interpreted as enhanced filler-matrix interactions. This phenomenon was also detected for PA-6/MWCNT/GF laminates [28], and can be attributed to a more inhomogeneous amorphous phase in the composites in relation to that of the pure matrix. Overall it can be concluded that the use of a compatibilizing agent with high $T_{g}$ and dual affinity with the matrix and the CNTs enhances the dynamic mechanical properties of hierarchical fiber-reinforced composites.

\subsection{Static mechanical properties}

Table 4 summarizes the percentage of variation reported in the mechanical properties of CNT-reinforced hierarchical composites with respect to the corresponding binary matrix/fiber samples. The results indicate that, in general, the enhancements in the fiber-dominated properties (i.e. Young's modulus and tensile strength) are lower than those achieved in the matrix-dominated properties (i.e. flexural and interlaminar shear strength).

\subsubsection{Tensile and flexural}

Globally, CNTs can be considered to have a positive effect on the tensile and flexural properties of fiber-reinforced thermoplastic composites, albeit the enhancement depends strongly on the type, source, purity, aspect ratio, concentration, orientation and degree of dispersion of the nanotubes as well as on the nature of the matrix. Regarding high-performance and engineering thermoplastics 
Table 4

Improvement in the mechanical properties (in\%) of CNT-reinforced thermoplastic hierarchical composites.

\begin{tabular}{|c|c|c|c|c|c|c|c|c|c|c|}
\hline Matrix & Fiber (wt.\%) & CNT (wt\%) & $E(\%)$ & $\sigma_{y}(\%)$ & $G(\%)$ & $E_{f}(\%)$ & $\sigma_{f M}(\%)$ & IFSS (\%) & ILSS (\%) & Ref. \\
\hline PEEK & GF (64) & Arc SWCNTs $(1.0)$ & 2.6 & -2.8 & -6.2 & 5.2 & 7.7 & & 3.8 & {$[35,36]$} \\
\hline PEEK & GF (64) & Laser SWCNTs (1.0) & 6.4 & -2.0 & -3.8 & 12.8 & 9.0 & & -21.6 & {$[35,36]$} \\
\hline PEEK & GF (64) & PEES-wrapped laser SWCNTs (0.5) & 9.6 & 8.4 & 12.5 & 14.5 & 13.5 & & 11.9 & {$[35,36]$} \\
\hline PEEK & GF (64) & PEES-wrapped laser SWCNTs (1.0) & 16.0 & 7.6 & 10.0 & 32.6 & 17.9 & & 64.4 & {$[35,36]$} \\
\hline PEEK & GF (64) & PEES-wrapped arc SWCNTs (1.0) & 14.1 & 9.2 & 7.5 & 28.5 & 17.0 & & -25.5 & {$[35,36]$} \\
\hline PA-6 & GF (49) & MWCNTs (0.5) & & & & 16.5 & 35.0 & & & [37] \\
\hline PA-6 & GF (49) & MWCNTs (1.0) & & & & 21.0 & 32.0 & & & [37] \\
\hline PA-6 & GF (49) & MWCNTs (2.0) & & & & 15.0 & 15.0 & & & [37] \\
\hline PA-6 & GF (49) & MWCNTs (4.0) & & & & 2.2 & 14.2 & & & [37] \\
\hline PA- 6 & $\mathrm{BF}^{\mathrm{a}}(30)$ & MWCNTs (0.5) & 12.2 & 9.0 & & 35.4 & 41.0 & & & [48] \\
\hline PA-6 & $\mathrm{BF}(30)$ & MWCNTs (1.0) & 12.2 & 8.5 & & 37.4 & 41.0 & & & [48] \\
\hline PA- 6 & $\mathrm{BF}(30)$ & MWCNTs (1.5) & 8.1 & 6.5 & & 29.1 & 37.0 & & & [48] \\
\hline PA- 6 & $\mathrm{BF}(30)$ & MWCNTs (2.0) & 6.2 & 5.0 & & 32.5 & 37.0 & & & [48] \\
\hline PA- 6 & GF (5) & MWCNTs (0.12) & & 12.8 & & & & & & [28] \\
\hline PA-6 & GF (5) & MWCNTs (0.18) & & 14.7 & & & & & & [28] \\
\hline $\mathrm{PP}$ & $\mathrm{GF}^{\mathrm{b}}(68)$ & SWCNTs $(0.04)$ & & & & & & 36.6 & & [30] \\
\hline PP & $\mathrm{GF}(5)$ & MWCNTs & 40.0 & 39.2 & 24.0 & 36.0 & 43.0 & & & [23] \\
\hline PP & CF (5) & MWCNTs & 57.0 & 37.3 & 34.0 & 51.0 & 35.0 & & & [23] \\
\hline PP & CF (12) & CVD CNTs & 133.0 & 57.0 & & & & & & [44] \\
\hline PI & CF (15) & PE/PAM ${ }^{\mathrm{C}}$-modified CVD MWCNTs (1.0) & & & & & & & 65.0 & [46] \\
\hline PI & CF $(30)$ & MWCNTs (15) & 33.5 & 125.0 & 75.0 & 36.0 & 29.6 & & & [47] \\
\hline PI & $\mathrm{CF}(25)^{\mathrm{e}}$ & CNT $(1.0)^{\mathrm{e}}$ & 1.8 & 1.7 & & & & & & [49] \\
\hline PI & $\mathrm{CF}(25)^{\mathrm{e}}$ & CNT $(3.0)^{\mathrm{e}}$ & 3.0 & 8.7 & & & & & & [49] \\
\hline PI & $\mathrm{CF}(25)^{\mathrm{e}}$ & CNT $(5.0)^{\mathrm{e}}$ & 6.0 & 17.4 & & & & & & {$[49]$} \\
\hline PMMA & $\mathrm{CF}^{\mathrm{d}}$ & MWCNTs & & & & & & 26.0 & & {$[42]$} \\
\hline PMMA & Silica ${ }^{d}$ & Short MWCNTs & & & & & & 150.0 & & [43] \\
\hline PMMA & Silica $^{\mathrm{d}}$ & Long MWCNTs & & & & & & 80.0 & & [43] \\
\hline
\end{tabular}

E: Young's modulus; $\sigma_{y}$ : tensile strength at yield; $G$ : impact strength; $E_{f}$ : flexural modulus; $\sigma_{f M}$ : flexural strength; IFSS: interfacial shear strength; ILSS: interlaminar shear strength.

a Basalt fiber.

${ }^{b}$ Glass fiber yarns.

c Polyethylene/polyamine.

d Composites with CNT-grafted fibers.

e Content in vol.\%.

like PEEK and PA-6, respectively, significant improvements in flexural properties (up to $41 \%$ [48]) have been reported, attributed to a stiffer CNT-reinforced matrix, enhanced fiber-matrix interfacial adhesion and/or strong synergetic effect between nano and micro-scale fillers. However, only slight improvements in the inplane Young's modulus $(E)$ and tensile strength $\left(\sigma_{y}\right)$ (up to $16 \%$ and $9 \%$, respectively [35]) have been attained. In particular, the addition of $1.0 \mathrm{wt} . \%$ arc and laser-SWCNTs wrapped in PEES to PEEK/GF raised the flexural modulus $\left(E_{f}\right)$ by about $29 \%$ and $33 \%$, respectively, whilst the increments in $E$ were significantly lower, around $14 \%$ and $16 \%$. However, $E$ and $E_{f}$ of non-compatibilized composites were on average $10 \%$ and $20 \%$ lower than the corresponding compatibilized samples, and their $\sigma_{y}$ was even lower than that of PEEK/GF, ascribed to a weaker nanotube-matrix interfacial bonding and the presence of SWCNT agglomerates. It should be highlighted that the relative increments in both moduli found in these hierarchical composites were higher than those reported for binary PEEK/SWCNT nanocomposites [73], ascribed to a cooperative effect of both fillers on enhancing the stiffness of the polymer. An analogous synergistic effect was described by Zhang [47] for high-performance PI/MWCNT/CF composites, where the mechanical properties of the hybrid samples were systematically higher than those of PI/MWCNT and PI/CF composites. CNTs may act as bridges between the polar fibers and the non-polar matrix, resulting in a better interlock of the fibers. Contrary to the behavior observed for other high-performance composites, an exceptional increase in $\sigma_{y}$ of $\sim 125 \%$ was reported upon addition of $15 \mathrm{wt} . \%$ MWCNTs to PI/CF, considerably larger than the $30 \%$ improvement found for the flexural strength $\left(\sigma_{f M}\right)$. This suggests that the primary effect of the nanofillers is a strengthening of the fiber-matrix interface rather than reinforcing the thermoplastic matrix. On the other hand, both tensile and flexural properties were found to be signif- icantly influenced by the CNT type. The increments obtained upon incorporation of laser-grown SWCNTs to PEEK/GF were significantly higher than those achieved with the same amounts of arcpurified SWCNTs [35], pointing towards the higher quality of the former nanofillers. With regard to the CNT content, the improvements in $E_{f}$ and $E$ of PEEK/GF attained at $1.0 \mathrm{wt}$.\% SWCNT loading ( $\sim 33 \%$ and $16 \%$, respectively) were around double those found with 0.5 wt.\% ( $\sim 15 \%$ and $9 \%$ ). Similarly, Ruiya et al. [49] found a quasi-linear increase in the tensile properties of $\mathrm{PI} / \mathrm{CF}$ upon increasing nanotube content, with increments of up to $6 \%$ and $18 \%$ in $E$ and $\sigma_{y}$ at 5.0 vol.\% CNT, respectively. This trend contrasts with the behavior reported by Meszaros et al. [48] for basalt fiber (BF)-reinforced PA-6/MWCNT hybrids, where the tensile and flexural properties reached similar values at 0.5 and $1.0 \mathrm{wt}$.\% CNT content (i.e. $\sim 12 \%$ and $35 \%$ increase in $E$ and $E_{f}$, respectively) and then dropped slightly due to a less effective strengthening effect. Analogous behavior was described by Shen et al. [37] for PA-6/GF/ MWCNT laminates. Here $E_{f}$ and $\sigma_{f M}$ increased by about $20 \%$ and $35 \%$ at MWCNT loadings of 1.0 and 0.5 wt.\%, respectively, subsequently decreasing significantly at higher concentrations, although the absolute values were still superior to those of samples without MWCNTs. However, for binary PA-6/MWCNT composites [37] both parameters increased progressively with the nanotube content up to $20 \%$ and $16 \%$, respectively, at 4 wt.\% loading. The authors stated that several factors such as CNT dispersion, the viscosity of the matrix and the corresponding wetting with the GF strongly condition how the increases in matrix properties are translated into the final mechanical performance of the laminates. The benefits of using a nanocomposite matrix resin with enhanced flexural properties, i.e. 4\% MWCNT in PA-6, for the fabrication of the laminates was offset by its high viscosity that caused poor impregnation of the $\mathrm{CF}$ tows. In CNT-modified epoxy/CF laminates Kim et al. [81] also 
found that, apart from the degree of CNT dispersion, the viscosity of the CNT/matrix mixture was the most important factor influencing the flexural properties of multiscale composites. The use of longer sonication times led to a very high blend viscosity that inhibited complete fiber wetting. As mentioned earlier, this issue can be circumvented by fabricating the laminates via electrostatic assembly, as described by Zhang et al. [28] for PA-6 hybrid composites. Thus, the addition of MWCNT contents lower than 0.2 wt.\% enhanced $\sigma_{y}$ of PA-6/GF by about $15 \%$.

With regard to hierarchical composites based on commodity plastics such as PP, strong improvements in both tensile and flexural properties have been attained $[23,44]$. In particular, $E$ and $E_{f}$ of samples reinforced with 5.0 wt.\% MWCNT-coated short CFs increased by up to $57 \%$ and $51 \%$, respectively, and those of composites incorporating the same amount of MWCNT-coated short GFs improved by around $40 \%$ and $36 \%$ compared to neat short fibercomposites [23]. Interestingly, the improvement was even more significant at higher fiber contents, up to $133 \%$ enhancement in E upon addition of $12.0 \mathrm{wt}$.\% coated CFs [44]. This behavior points towards a more efficient fiber-matrix stress transfer due to the CNT coating and the existence of synergistic effects of both fillers on reinforcing the matrix.

The incorporation of SWCNTs has been demonstrated to affect the elongation at break of polymer/fiber composites such as PEEK/GF [35]. As reported for binary nanocomposites, the nanotubes obstruct the drawing process of the matrix, restricting its ex- tent of plastic deformation. Nevertheless, it was found that the addition of a compatibilizer reduced the stress concentrations at the polymer-nanotube interface, thereby improving the composite ductility. Thus, the compatibilized laminates displayed similar elongation at break to that of the reference PEEK/GF. However, composites with 1.0 wt.\% non-wrapped SWCNTs showed around $40 \%$ reduction in strain at break, ascribed to the presence of nanotube agglomerates that hinder the ductile flow of the matrix chains. Further, this parameter decreased with increasing SWCNT loading; when the concentration was doubled, a 20\% drop was observed. As the concentration rises it is more difficult to perfectly disperse the SWCNT bundles within the polymer matrix, even in the presence of a compatibilizer. In contrast, the addition of MWCNTs hardly modifies the elongation at break of hierarchical composites, as reported for BF/PA-6/MWCNT hybrids [48], since MWCNTs are easier to disperse than SWCNTs. Thus, the elongation at break is indicative of the quality of the CNT dispersion in thermoplastic composites.

Fig. 8 presents a comparison of the tensile and flexural properties of hierarchical thermoplastic-based composites versus traditional fiber-reinforced ones including the best-in-class commercial materials. Prior to analyzing the data, it is important to note that the aim of the plot is simply to provide a general idea of the range of properties for each material since it is difficult to establish a direct and precise comparison between them due to the large number of parameters influencing their mechanical
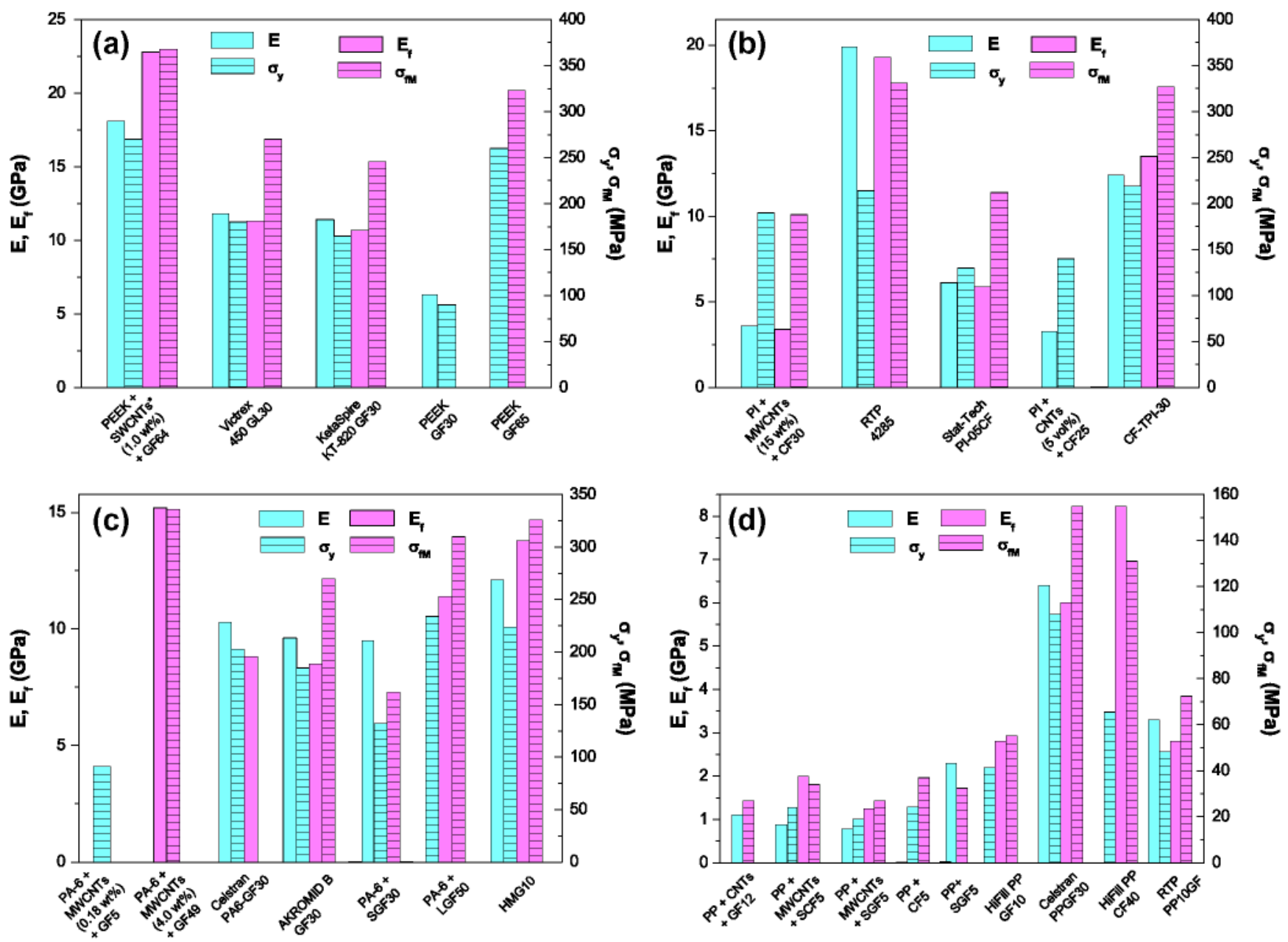

Fig. 8. Comparison of the tensile and flexural properties of: (a) PEEK/GF hierarchical laminate reinforced with 1.0 wt.\% SWCNTs wrapped in PEES [35] vs. traditional GFreinforced PEEK composites included in Table $1[50,51,54]$. The asterisk indicates SWCNTs wrapped in PEES. (b): Pl/CF hierarchical composites reinforced with 15 wt.\% MWCNTs [47] and 5.0 vol.\% CNTs [49] vs. conventional CF-reinforced Pl composites [55-57]. (c) PA-6/GF laminates reinforced with 0.18 [28] and 4.0 wt.\% MWCNTs [37] vs. traditional GF-reinforced materials [59-61,63,64]. (d) CNT-coated CF and GF-reinforced PP composites [10,30] vs. conventional fiber-reinforced PP composites [55,59,65-67]. 
properties, including the processing method and conditions, the matrix properties, crystallinity and molecular weight as well as the fiber modulus, length, diameter, aspect ratio, content, surface state, orientation and distribution, amongst others. Regarding GFreinforced composites based on PEEK (Fig. 8a), it is found that the compatibilized hybrid laminate incorporating $1.0 \mathrm{wt} . \%$ laser SWCNTs wrapped in PEES [35] exhibits the optimum performance, with slightly improved properties in comparison to laminates incorporating similar GF contents [54], and considerably higher $E$ and $E_{f}$ (by $\sim 55 \%$ and $100 \%$, respectively) than current commercial products [50,51]. This exceptional behavior arises from the use of SWCNTs synthesized by the laser-ablation method. The laser process produces CNTs of the highest quality (very high purity, few defects, high crystallinity, extremely large aspect ratio, etc.) as compared to any other synthesis methods [82]. Moreover, the use of a compatibilizer significantly enhances the nanotube dispersion and the adhesion with the matrix. However, in the case of CFreinforced composites based on PI (Fig. 8b), the hybrids incorporating CNTs $[47,49]$ display poorer performance than commercial materials [55] or conventional composites [57] with similar amount of CF. Apart from the above-mentioned wide number of factors influencing the mechanical performance, this behavior is likely to be due to the use of commercial CNTs with high amorphous carbon content and/or metal impurities, as well as the direct incorporation of the nanotubes into the matrix without predispersion, surfactant or modifier strategies. A careful selection of the CNTs, a detailed study of their characteristics and preliminary tests to evaluate their dispersion within the matrix are essential prior to the development of the hybrid composites. Focusing on GF-reinforced PA-6 materials (Fig. 8c), it is found that those with relatively high amount of MWCNTs (i.e. $4.0 \mathrm{wt}$ \% [37]) exhibit improved performance over the commercial counterparts [59-61] and conventional composites reinforced with similar GF loadings [63]. In contrast, those incorporating very low MWCNT content (i.e. 0.18 wt.\%) and low CF loading display poorer properties [28]. This suggests that the amount of both micro- and nanofillers in the hierarchical composites need to be optimized. In particular, it is desirable that the CNT content be relatively low to avoid agglomeration and large viscosity increments, but high enough to provoke a significant influence on the material properties. In the case of composites based on PP (Fig. 8d), both CF and GF-reinforced hybrids $[23,44]$ display lower modulus and strength than current commercial products $[55,59,65]$ and comparable to those reported for traditional composites with similar amount of fibers [66,67]. The differences observed are undoubtedly related to their manufacturing process, since the hierarchical materials were prepared by growing the CNTs onto the fibers, an approach that makes it difficult to control the CNT content, length, orientation and degree of dispersion, resulting in very dense and entangled nanotube bundles. In fact, the apparent thickness of the microscale fibers was almost doubled upon CNT coating on their surface [23], and it has been reported that an increase in the fiber diameter has detrimental effect on the mechanical properties of the composites [61]. The growth conditions of the CNTs onto the fibers should be carefully selected to attain a uniform thin coating composed of long, disentangled and aligned CNTs with a narrow distribution of diameters [24].

There have been very few studies modeling the mechanical properties of CNT-based hierarchical composites [81,83]. Their tensile properties can be predicted using a combination of the HalpinTsai equations [84], which are often used to predict the bulk mechanical properties of CNT-based nanocomposites, with a micromechanical approach [81] that is widely applied for traditional fiber-reinforced composites. However, it is not clear whether methodologies developed for conventional composites such as Halpin-Tsai can be properly applied to CNT-systems due to effects of scale or curvature. Another option is to apply a two-phase model [35]. Firstly, the theoretical values for polymer/CNT mixtures can be calculated according to the well-known rule of mixtures for discontinuous reinforcement. Since the CNTs are not perfectly extended when dispersed in a polymer matrix, a decreased shape factor $(1 / 5)$ should be considered [85]. The CNT-reinforced polymer is then regarded as a new matrix phase and the fibers as the filler phase. The rule of mixtures can be subsequently applied to calculate the laminate modulus: $E_{c}=\zeta_{E} V_{f} E_{f}+\left(1-V_{f}\right) E_{m}$, where $\zeta_{E}$ is the fiber efficiency factor ( $\sim 0.5$ for continuous bidirectional fibers), $E_{f}$ and $E_{m}$ are the fiber and matrix modulus, respectively, and $V_{f}$ the fiber volume fraction. Using this approach, the modulus of PEEK/ SWCNT (1.0 wt.\%)/GF laminates was estimated to be $13-27 \%$ higher than the measured data [35]. The discrepancies between experimental and calculated values were ascribed to several factors, mainly the very high viscosity of the PEEK/SWCNT mixture that precludes perfect fiber wetting, and the fact that the SWCNTs are gathered in small bundles and shear slippage of individual nanotubes within the bundle may occur, thereby limiting stress transfer from the matrix to the nanofillers. It should be highlighted that the rule of mixtures is an upper boundary expected in the case of perfect CNT dispersion and adhesion to the matrix. New analytical models should be developed that can tackle more precisely these aspects.

\subsubsection{Impact strength}

It is known that several factors control the impact strength of reinforced composites [86], including a diminishing effect of the fillers on the toughness due to a drastic decrease in the elongation at break, and hence a reduction of the area under the stress-strain curves. In addition, stress concentrations can be formed around the filler ends, an area of poor filler-matrix adhesion. Another is a positive effect due to the fact that fillers reduce the crack propagation rate by forcing cracks to circumvent them. Moreover, the increase of fracture resistance is the result of energy-dissipating mechanisms based on filler bridging, debonding, slip and pull-out. The net effect depends on the competition of these factors. In the case of laminates including CNTs, the toughness is sensitive to their size, state of dispersion and interfacial adhesion with the matrix. Recently, the toughness of SWCNT-reinforced PEEK/GF composites was measured via Charpy impact tests [35]. It was found that the addition of $1.0 \mathrm{wt} . \%$ non-wrapped arc and laser-SWCNTs slightly decreased the impact resistance, whereas the same amount of SWCNTs dispersed in PEES increased this property by an average of $9 \%$. The composite reinforced with 0.5 wt.\% wrapped lasergrown SWCNTs displayed the highest impact strength, with around a $13 \%$ increase in comparison to that of PEEK/GF. The reduction in toughness of the non-compatibilized samples was attributed to the presence of small agglomerates that act as stress concentration sites promoting the formation of dimples and nucleating cracks, thus resulting in premature system failure. However, the toughness was improved moderately by the addition of a compatibilizer due to a more homogeneous nanofiller dispersion that minimizes the number of stress concentration nuclei, as well as providing an enhanced CNT-matrix interfacial adhesion, which provides an effective barrier for pinning and bifurcation of the advancing cracks. In particular, the enhanced behavior of the laminate with 0.5 wt.\% wrapped laser-grown SWCNTs was ascribed to several synergistic effects: high nanofiller quality, enhanced dispersion due to the low nanotube content wrapped in PEES and the presence of the GFs that also have a positive effect on the impact resistance of the polymer. Stronger improvements in impact strength have been reported for PP composites containing CNTcoated fibers. Thus, the addition of MWCNTs to CF and GF-reinforced PP increased the impact resistance by $34 \%$ and $24 \%$, respectively [23], ascribed to an enhanced fiber-matrix interfacial region 
and the combined reinforcement effect of CNTs and fibers. Similar cooperative effects of both micro- and nano-scale fillers on toughening the matrix have been reported for epoxy/GF [33] and epoxy/ $\mathrm{CF}$ [87] composites, where improvements in fracture toughness of up to $75 \%$ were attained upon addition of $0.1-1.0 \mathrm{wt} \%$ MWCNTs. The same enhancement was reported for $\mathrm{PI} / \mathrm{CF}$ composites upon addition of $15 \mathrm{wt} \%$ MWCNTs [47]. A strong 3D network can be developed by the introduction of the CNTs that prevents the initiation of shear failure in the composites. Failure usually involves the pull-out, rupture or bridging of the nanofillers, which is claimed to consume additional energy and hence contributes significantly to the enhanced toughness.

\subsubsection{Interlaminar and interfacial shear strength}

The interlaminar shear strength (ILSS) gives information about the fiber/matrix interfacial adhesion and can be assessed using short beam shear (SBS) or compression shear tests (CSTs). It has been reported that the ILSS of hierarchical composites containing nanotubes in the interlaminar region can be increased by $2-45 \%$ depending on the CNT type, content and surface chemistry [40]. The use of functionalized CNTs led to greater improvements over pristine CNTs [22] due to stronger interfacial bonding between the nanotubes and the matrix. In the case of laminates incorporating CNTs around the fibers larger improvements in ILSS have been attained, up to $69 \%$ for epoxy/MWCNTs/alumina fiber composites [88]. Nevertheless, many factors are known to play a role in laminate ILSS, including the degree of porosity, interlaminar layer thickness and crystallinity. Ashrafi et al. [36] evaluated the ILSS of PEEK/SWCNT/GF composites using SBS. In comparison to binary PEEK/GF, laminates incorporating laser SWCNTs wrapped in a compatibilizing agent demonstrated a $64 \%$ and $12 \%$ increase for loadings of 1.0 and $0.5 \mathrm{wt} . \%$, respectively. These strong improvements in ILLS were attributed to the high quality (very low void content) of the laminates combined with enhanced nanotube dispersion within the polymer matrix, resulting in hindered crack growth inside the matrix region through SWCNT bridging effects. In contrast, for the non-compatibilized composites and those incorporating arc SWCNTs, either no change, or a reduction in this property was measured as compared to the baseline laminate. A combination of different mechanisms such as compression failure, inelastic deformation, fiber failure and shear failure was claimed to be responsible for the fracture of these nano-modified laminates. Recently, Li and Bai [46] reported a 65\% increase in the ILSS of PI/ CFcomposites upon addition of polyethylene-polyamine surface treated CNTs, attributed to an improvement in the matrix strength, an increase in the $\mathrm{CF}$ surface roughness and a stronger fiber-matrix interfacial bonding. The roughness and strong interfacial adhesion acted as mechanical interlocking and increased the frictional coefficient, thereby leading to higher ILSS.

The nature of the fiber/matrix interface plays a key role in both composite processing and ultimate performance. For this reason wide number of studies have considered the interfacial properties of CNT-grafted CF multiscale composites by measuring the interfacial shear strength (IFSS) through single fiber fragmentation tests $[27,42,43,89]$. Grafting CNTs onto fibers can significantly increase the fiber surface area and improve the fiber-matrix interfacial load transfer through the CNT grafted layer. IFSS improvements in the range of $11-470 \%$ have been reported depending on the CNT type, concentration, length and alignment. Qian et al. [42] reported a $26 \%$ enhancement in the IFSS of PMMA/CF composites upon growing MWCNTs onto the fibers using the CVD method, due to the enhanced wettability of the CNT-grafted fibers, demonstrated by contact angle measurements, and the mechanical interlocking between MWCNTs and the matrix. The same authors also measured the IFSS of PMMA/MWCNT/silica fiber composites [43] and found that the degree of improvement was strongly influenced by the length and morphology of the grafted CNTs. Shorter MWCNTs of $\sim 2 \mu \mathrm{m}$ that were symmetrically accommodated around the primary fibers led to a dramatic increase of up to $150 \%$ in the IFSS, whilst longer asymmetrical MWCNTs of around $\sim 10 \mu \mathrm{m}$ caused uneven stress transfer and only resulted in an $80 \%$ enhancement. The development of hierarchical composites comprising CNTgrafted fibers cannot only improve IFSS, but also provides a controlled method for introducing high contents of oriented CNTs into the matrix surrounding the fibers, which should improve critical engineering properties of conventional continuous fiber-reinforced composites such as transverse stiffness, longitudinal compression strength and interlaminar shear strength.

A recent study [38] analyzed the interphase properties of SWCNT-reinforced PEEK/GF laminates using nanoindentation. The paper demonstrates that the polymer-fiber interface can be easily detected using the continuous stiffness measurement (CSM) technique, and provides experimental evidence that the extent of the interphase increases if the polymer matrix is reinforced with SWCNTs, particularly those wrapped in a compatibilizing agent. The authors carried out a mapping of the mechanical properties using nanoindentation, and were able to accurately reproduce the surface topography and locate the interphase properties at the boundary between the fibers and the matrix. It can be concluded that multiscale reinforcement is a convenient route to provide polymer-fiber laminates with improved interphases.

\subsubsection{Fractographic analysis}

Fractographic analysis is an essential tool for understanding composite structural behavior, and has been used to study the influence of CNTs on the failure mode of hierarchical composites. Fractured surfaces of PEEK/SWCNT/GF laminates examined after flexural tests using SEM [35] (Fig. 9) demonstrated that fiber fracture dominated the failure mechanism, combined with resin yielding at the fracture zone, suggesting that tensile stresses were the main cause for failure. Moreover, CNT pull-out instead of CNT breaking was found to be the result of flexural deformation where crack propagation was delayed by the pulling force of the CNTs at the crack surface due to an energy dissipation phenomenon. This increased the delamination resistance in comparison to the baseline laminate. In the case of non-compatibilized composites (Fig. 9a and b) only a few SWCNTs were found to protrude out of the matrix, while in the compatibilized composites (Fig. 9c and d) several SWCNTs were pulled-out of the matrix and others were observed at the matrix-fiber interface extending into the surrounding matrix, which is known to stiffen the matrix and provide increased lateral support for the load-bearing microscale fibers. Qian et al. [43] characterized the cross-sections of PMMA/ MWCNT/silica fiber specimens fractured in flexion using SEM (Fig. 10). In composites both with and without CNTs the fracture plane was found at the fiber/matrix interface. However, composites with as-received silica fibers (Fig. 10a and b) showed de-bonding at the interface, hinting towards a weak fiber-matrix interfacial adhesion, whereas in the CNT-grafted samples (Fig. 10c and d) a strong interface was observed that limited de-bonding. The failure occurred at or near the root of the CNTs, suggesting that the shear strength between the CNTs and the fibers was greater than that between the matrix and the fibers. Moreover, the CNTs were completely embedded in the polymer matrix indicating excellent wettability by the PMMA. The same authors analyzed the fracture morphology of PMMA/MWCNT/CF composites [42] and also found that the failure mode was not affected by the CNT grafting. The diameter of the CFs remained unchanged after the fracture, demonstrating that no cohesive mechanism had occurred, which is in contrast to the behavior reported for epoxy/CNT-grafted CF composites [90] where the failure plane was found within the fibers. The mechanistic difference was ascribed to variations in the intrin- 

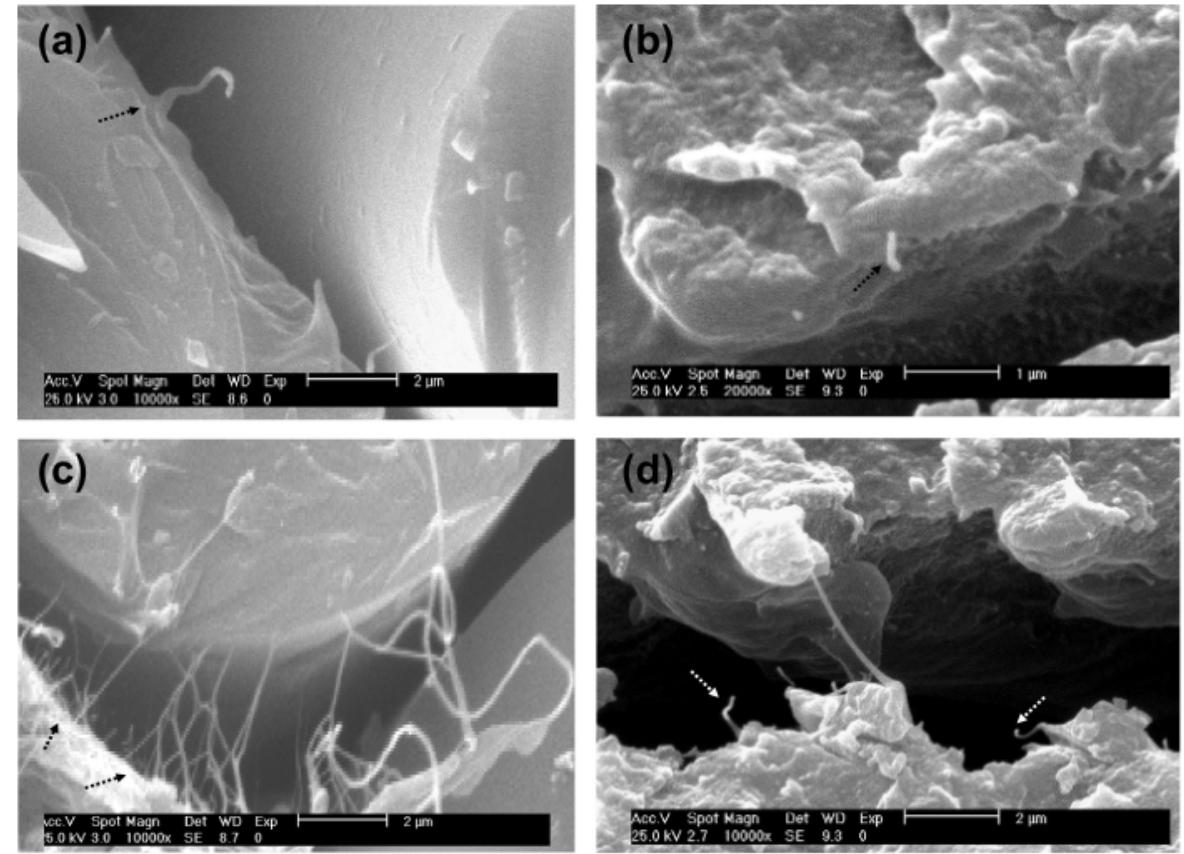

Fig. 9. SEM micrographs from fractured surfaces of flexural specimens: (a) and (b) PEEK/laser (1.0 wt.\%)/GF; (c) and (d) PEEK/laser (1.0 wt.\%) + PEES/GF. (a) and (c) were taken from a region adjacent to the fiber tows, whilst (b) and (c) correspond to matrix-rich areas. The dashed arrows point out SWCNTs pulled-out of the matrix. Adapted from Ref. [35], copyright 2011, with permission from Elsevier.
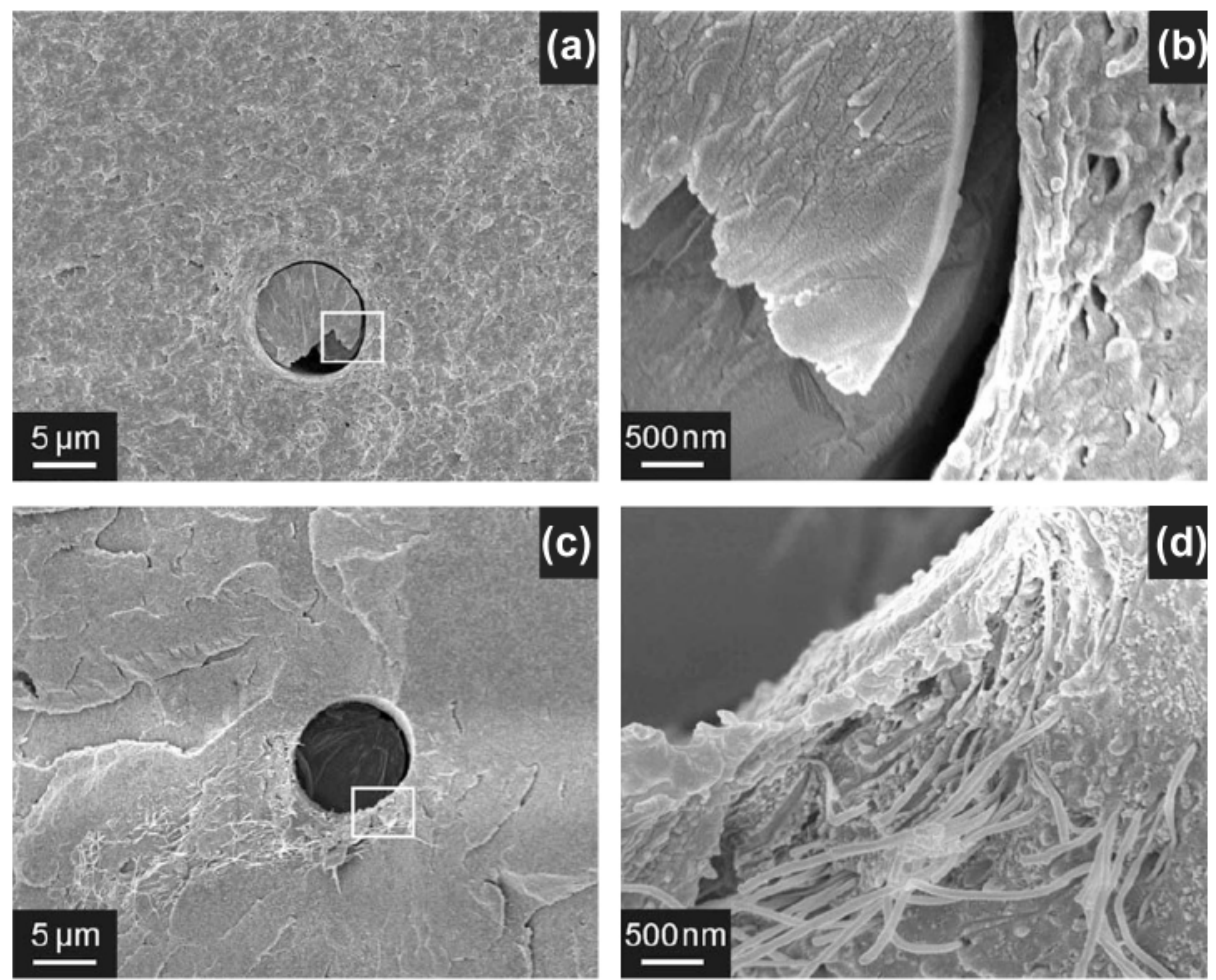

Fig. 10. SEM images of the fracture surfaces of PMMA/silica fiber composites (a), (b) without and (c), (d) with CNTs grafted onto the fibers. The micrographs in (b) and (d) are a magnification of (a) and (c), respectively. From Ref. [43], copyright 2010, with permission from Elsevier.

sic microstructure of the fibers, CNT grafting density or surface damage during the grafting reaction.

The fractured surfaces of PP/CNT-coated fiber composites after impact tests were also analyzed by SEM [23] (Fig. 11). In samples with neat CFs and GFs (Fig. 11a and c), the fiber surface appeared smooth, without signs of interfacial fiber-matrix interactions, whilst in the hierarchical composites (Fig. 11b and d) the fractured fibers showed a rough surface and some PP residue, indicative of an effective CNT grafting onto the fibers and a CNT-PP micromechanical coupling. Similar observations were reported by Zhang et al. [28] for PA-6/MWCNT/GF composites, where the fiber surface appeared irregular and coarse after tensile tests. Further, most of the fibers remained embedded in the matrix without protruding from the fractured surface, indicating enhanced fiber-matrix adhe- 

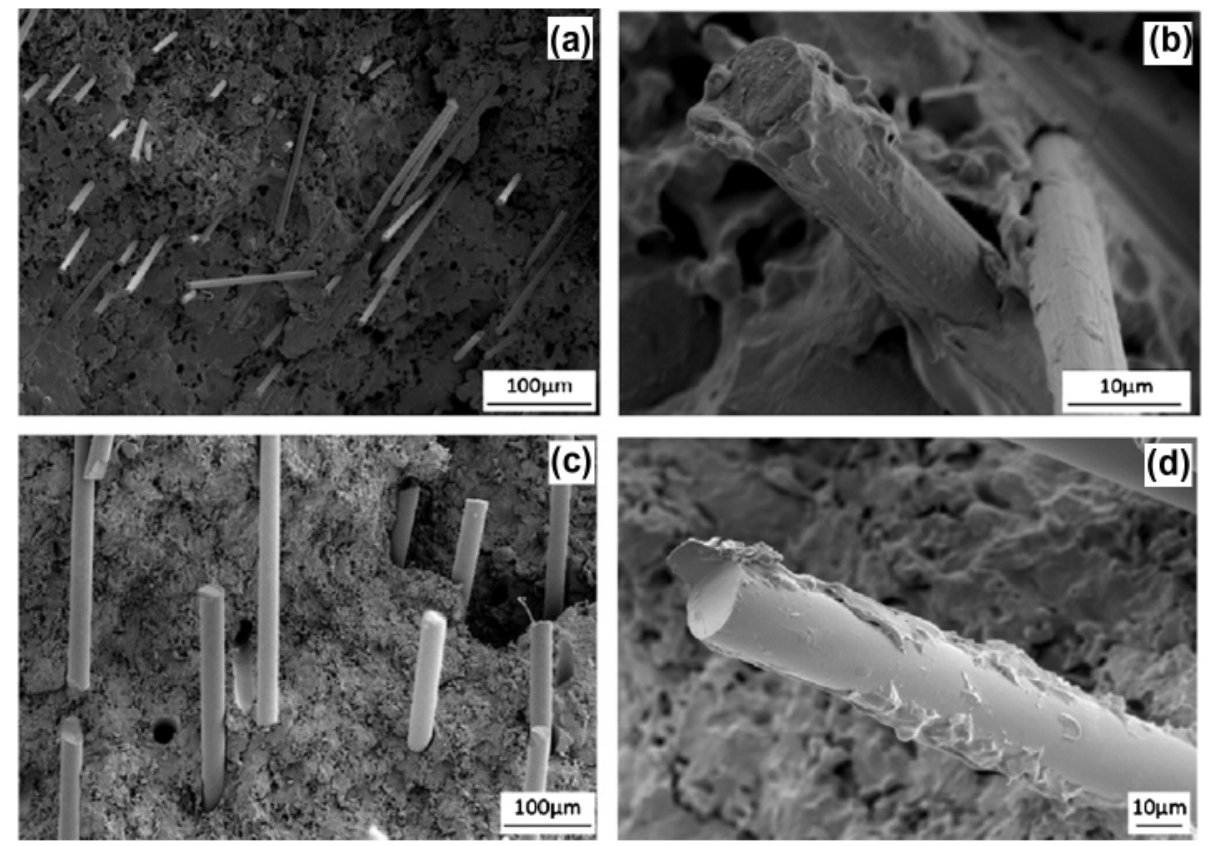

Fig. 11. SEM images of impact fractured surfaces of: (a) PP/CF; (b) PP/CNT-coated CF; (c) PP/GF; (d) PP/CNT-coated GF. The fiber surfaces are smooth in (a) and (c), while show some PP residue in (b) and (d). From Ref. [23], copyright 2013, with permission from Elsevier.

sion. Strong CNT-fiber and CNT-matrix interactions increased the fiber-matrix de-bonding energy, the energy for crack growth and for fiber pull out, resulting in strong improvements in impact resistance.

\subsection{Electrical conductivity}

Hierarchical composites incorporating CNTs have been reported to exhibit enhanced electrical conductivity $[21,22]$ arising from the network-formation ability of the CNTs above the percolation threshold. Their conductive properties depend strongly on concentration, aspect ratio, and dispersion degree of the CNTs, as well as on filler-matrix and filler-filler interfacial interactions. The CNT quality and type also play an important role on their electrical behavior. Thus, laminates reinforced with pristine laser grown CNTs display higher conductivity in comparison to those incorpo- rating acid-functionalized CNTs [36], since the sonication process used during the functionalization can damage and shorten the CNTs, with consequent detrimental effects on their conductivity. Another factor that influences this property is polymer wrapping [35], and its effect has been found to be twofold. On the one hand, it disrupts the formation of a conductive network hence reducing electrical conductivity. On the other, it leads to a better nanotube dispersion that improves the electron charge transfer. Indeed the disadvantages of wrapping with respect to CNT conductivity appeared to be compensated for by the enhanced dispersion and adhesion, and laminates with wrapped and non-wrapped CNTs showed approximately the same conductivity. Further, a strong degree of anisotropy has been observed for GF-reinforced composites such as those based on a PEEK matrix [35], where the in-plane conductivity was in the range of $10^{-6}-10^{-4} \mathrm{~S} / \mathrm{cm}$, about an order of magnitude higher than the out-of-plane conductivity due to the

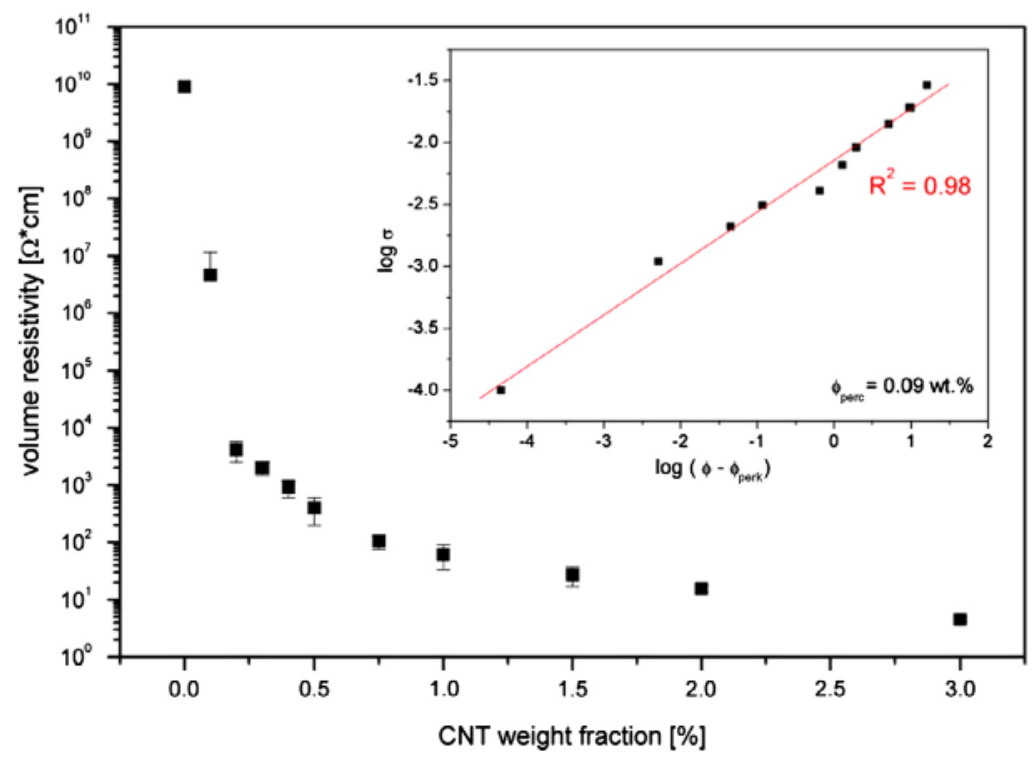

Fig. 12. Volume resistivity as a function of CNT weight fraction for MWCNT-modified-GF yarns embedded into a PP matrix. The inset shows the best linear fit of the experimental data in order to determine the percolation threshold, $\varphi_{c}=0.09$ wt.\%. Adapted from Ref. [31], copyright 2010, with permission from Elsevier. 
development of effective conductive CNT paths in the flow direction. This behavior is not expected in composites based on CFs, since the high conductivity of these fibers would mask any anisotropic effect of the nanotubes.

Rausch and Mäder [31,32] investigated the electrical conductivity of CNT-coated GF yarns embedded in a PP matrix (Fig. 12). As typically observed for binary polymer/CNT nanocomposites, the volume resistivity decreased with increasing CNT concentration showing a sudden change around the percolation threshold. A $\log -\log$ plot of the conductivity versus CNT content was employed to determine the percolation threshold (inset, Fig. 12). The best linear fit was obtained for $0.09 \mathrm{wt} . \%$ MWCNTs, a value lower than that obtained for melt-processed PP/CNT nanocomposites [91], which is indicative of the improved nanotube dispersion and demonstrates the potential of electrically conductive coatings. Theoretically, a very thin and homogeneous CNT layer on the GF surface is required to attain high conductivity, since this enables the formation of continuous conductive paths. However, as shown in Fig. 3, when GFs are sized or coated, the surface is not homogeneously nor completely covered by the sizing/coating, hence only a certain number of CNTs contribute to the charge transfer. On the other hand, conductivity was found to increase on reducing the GF yarn length [31], and for the same length it increased with the CNT weight fraction of the film former and the solid content of the CNT-coating, ascribed to a larger cross-sectional area. For coating contents below $10 \mathrm{wt} . \%$ the GF were inhomogeneously covered resulting in lower conductivity values. However, it should be pointed out that this concentration is system specific and will depend on the fiber wettability.

\section{Potential applications}

The study of hierarchical CNT-modified fiber-reinforced thermoplastic composites is still at a preliminary stage and, to the best of our knowledge, commercial applications are not yet available. Further development and optimization is required before they can be used at a large-scale. Nevertheless, these promising multifunctional materials are expected to have a wide range of industrial applications, primarily in the aeronautics, automobile and energy sectors. In particular, they can significantly reduce the weight in traditional structural composites, being well suited for aircraft parts such as wing elements, fuel tank manhole covers, pylon fairings, landing gear hubcaps as well as for automobile parts such as air intake systems, seals, fuel rails and valve covers. They can also be applied in wind turbine blades, bridges, solar panels, pressure vessels and tank pressurization lines. Further, these multiscale composites can be employed in energy storage devices, as the load-carrying structural body. These are highly important application areas that move towards the development of future zero-emission vehicles, requiring radical energy efficiency, sustainability and environmental friendliness. In addition, they are ideal candidates for energy-dependant applications, such as access panels for aircrafts, laptops and mobiles.

On the other hand, CNTs embedded in a sizing or polymer matrix can be used as health sensors to monitor damage [29,92]. For example, CNT-based strain sensors with excellent repeatability and stability have been developed by coating GF yarns with CNTs and embedding the resulting yarns in a PP matrix [31,32]. The formation of CNT networks on the GF allowed local strain mapping within the composite interphase, which can be used for health monitoring of GF-reinforced composites in a non-destructive way. The onset of GF breakage can be detected by a sudden decrease in electrical conductivity. Moreover, indirect information about the interphase strain can be derived from the slope of the resistance curve versus displacement, enabling to envisage when the interphase is about to fail, albeit the exact location of the interphase failure cannot be predicted. This is a new pathway towards the development of simple sensors and integrative switches at the micrometer-scale actuated by strain or temperature.

\section{Concluding remarks and future perspectives}

In this review, recent studies on hierarchical composites fabricated by the incorporation of CNTs into conventional fiber-reinforced thermoplastics have been analyzed. These multiscale materials can be prepared either by dispersing the CNTs into the polymer matrix or by growing or depositing them onto the fabric layers. Apart from the processing method, their properties are influenced by several factors including the CNT type, aspect ratio, quality, concentration, orientation, degree of dispersion and interfacial adhesion with the matrix. These aspects should be taken into account prior to composite manufacture and are essential for the interpretation of experimental observations. The effect of CNTs on the melting and crystallization temperatures, degree of crystallinity and glass transition temperature of the polymer matrix should be explored, since these parameters play a key role on the final properties of the materials. The use of both micro- and nano-scale can lead to synergistic effects that enhance the mechanical, thermal and electrical properties of the matrix. In particular, the addition of a small amount of SWCNTs wrapped in a compatibilizing agent was found to be very effective for improving the thermal conductivity and thermal stability of the composites, while the incorporation of MWCNTs resulted in strong enhancements in flame resistance and impact strength. Although the CNTs constitute a very small weight fraction of the laminates as a whole, they are able to modify their macroscopic mechanical properties, leading to simultaneous improvements in stiffness, strength and toughness compared to conventional fiber-reinforced thermoplastics. In general, remarkable enhancements in the matrix-dominated properties such as flexural and interlaminar shear strength could be found, whereas only slight increases in the fiber-dependent properties such as Young's modulus and tensile strength were reported. Composites comprising CNT-grafted fibers exhibit dramatically improved interfacial shear strength due to the enhanced wettability of the fibers, providing a controlled method for introducing high loadings of oriented CNTs into the matrix surrounding the fibers, and improving critical engineering properties of conventional continuous fiber-reinforced composites. The main driving force for using hierarchical composites filled with small amounts of CNTs in transport applications is weight reduction derived from an improved mechanical performance of the hybrid material at a reasonable cost. To make cost-effective the replacement of the traditional composites by the hierarchical ones, the weight reduction and costs of the raw materials and the processing methods should be balanced. In addition, cost savings in fuel consumption are highly desirable in order to develop more sustainable transport industries.

In summary, significant progress in the development of hierarchical thermoplastic-based composites has produced very promising results thus far. The main challenge that hinders the growth and application of these novel composites relates to the impregnation of the reinforcing fibres by very viscous CNT containing polymer melts. Further, to fully exploit the great potential of multiscale composites, scalable and cost-effective manufacturing processes that allow for their efficient production such as displaced foam dispersion (DFD) technique [93] or powder impregnation approaches should be developed. It is clear that some directed efforts are now required to employ the advantages obtained through these multifunctional high-performance materials in sectors such as the aeronautic, automobile and energy. It is envisaged that CNTs would be 
used at an industrial level as hybrid fillers in conventional composites, where simultaneous enhancements in thermal, electrical and mechanical properties are required.

\section{Acknowledgments}

This work was financially supported by a coordinated project between the National Research Council of Canada (NRC) and the Spanish National Scientific Research Council - Consejo Superior de Investigaciones Cientificas (CSIC), and by the Spanish Government - Ministry of Economy and Competitivity (MINECO) project MAT2010-21070-C02-01. MN acknowledges the MINECO for a Ramón y Cajal senior postdoctoral research fellowship, and $\mathrm{AD}$ would like to thank to the CSIC for a JAE postdoctoral research fellowship.

\section{References}

[1] Offringa AR. Thermoplastic composites in aerospace-proven through costeffective processing. In: 41th International conference on automated composites (ICAC), Nottingham, UK; 1995, p. 161-9.

[2] Marsh G. Next step for automotive materials. Mater Today 2003;6:36-43.

[3] Mouritz AP, Gellert E, Burchill P, Challis K. Review of advanced composite structures for naval ships and submarines. Compos Struct 2001;53:21-42.

[4] Mallick PK. Fiber reinforced composites: materials, manufacturing and design. 3rd ed. New York: CRC Press; 2008.

[5] Hollaway LC. The evolution of and the way forward for advanced polymer composites in the civil infrastructure. Construct Built Mater 2003;17:365-78,

[6] Brondsted P, Lilholt H, Lystrup A. Composite materials for wind power turbine blades. Annu Rev Mater Res 2005;35:505-38.

[7] Moritis G. Hub. New technologies provide access to more deepwater reserves. Oil Gas J 2003;101:54-61.

[8] Khan SU, Kim JK. Impact and delamination failure of multiscale carbon nanotube-fiber reinforced polymer composites: a review. Int J Aeronaut Space Sci $2011 ; 12: 115-33$.

[9] Kroll M, Langer B, Grellmann W. Toughness optimization of elastomermodified glass-fiber reinforced PA6 materials. J Appl Polym Sci 2013;127: 57-66.

[10] Hojo M, Ando T, Tanaka M, Adachi T, Ochiai S, Endo Y. Modes I and II interlaminar fracture toughness and fatigue delamination of CF/epoxy laminates with self-same epoxy interleaf. Int J Fatigue 2006;28:1154-65.

[11] Sadighi M, Alderliesten RC, Benedictus R. Impact resistance of fiber-metal laminates: a review. Int J lmpact Eng 2012;49:77-90.

[12] Tong L, Mouritz AP, Bannister MK. 3D Fibre reinforced polymer composites. Boston: Elsevier; 2002. p. 1-12.

[13] Mouritz AP, Leong $\mathrm{KH}$, Hersberg $\mathrm{l}$. A review of the effect of stitching on the inplane mechanical properties of fibre-reinforced polymer composites. Compos A Appl Sci Manuf 1997;28A:979-91.

[14] Mouritz AP. Review of z-pinned composite laminates. Compos A Appl Sci Manuf 2007; 38:2383-97.

[15] Ayranci C, Carey J. 2D braided composites: a review for stiffness critical applications. Compos Struct 2008;85:43-58.

[16] Fujihara K, Teo K, Gopal R, Loh PL, Ganesh VK, Ramakrishna S, et al. Fibrous composite materials in dentistry and orthopaedics: review and applications. Compos Sci Technol 2004;64:775-88.

[17] Jones FR. A review of interphase formation and design in fibre-reinforced composites. J Adhes Sci Technol 2010;24:171-202.

[18] Shubhra QTH, Alam AKMM, Quaiyyum MA. Mechanical properties of polypropylene composites: a review. J Thermoplast Compos Mater 2011;26: 362-91.

[19] Ji-Nian Y, Ai-Qin X. Phase structures and mechanical properties of SGF/PP composites with and without compatilizers. Adv Mater Res 2013;668:33-6.

[20] Mittal V. Polymer nanotube nanocomposites: synthesis, properties and applications. New Jersey: Wiley-Scrivener; 2010.

[21] Gojny FH, Wichmann MHG, Fiedler B, Bauhofer W, Schulte K. Influence of nano-modification on the mechanical and electrical properties of conventional fiber-reinforced composites. Compos A Appl Sci Manuf 2005;36:1525-35.

[22] Qiu JJ, Zhang C, Wang B, Liang R. Carbon nanotube integrated multifunctional multiscale composites. Nanotechnology 2007;18:275708-11.

[23] Rahmanian S, Thean KS, Suraya AR, Shazed MA, Salleh MAM, Yusoff HM. Carbon and glass hierarchical fibers: influence of carbon nanotubes on tensile, flexural and impact properties of short fiber reinforced composites. Mater Des 2013;43:10-6.

[24] Garcia EJ, Hart AJ, Wardle BL, Yamamoto N. Fabrication and multifunctional properties of hybrid laminate with aligned carbon nanotubes grown in situ. Compos Sci Technol 2008;68:2034-41.

[25] Abot JL, Song Y, Schulz MJ, Shanov VN. Novel carbon nanotube arrayreinforced laminated composite materials with higher interlaminar elastic properties. Compos Sci Technol 2008;68:2755-60.

[26] Qian H, Greenhalgh ES, Shaffer MSP, Bismarck A. Carbon nanotube-based hierarchical composites: a review. J Mater Chem 2010;20:4751-62.
[27] Bekyarova E, Thostenson ET, Yu A, Kim H, Gao J, Tang J, et al. Multiscale carbon nanotube-carbon fiber reinforcement for advanced epoxy composites. Langmuir 2007;23:3970-4

[28] Zhang L, Su D, Jin L, Li C. Polyamide 6 composites reinforced with glass fibers modified with electrostatically assembled multiwall carbon nanotubes. J Mater Sci 2012;47:5446-54.

[29] Barber AH, Zhao Q Wagner HD, Baillie CA. Characterization of E-glasspropylene interfaces using carbon nanotubes as strain sensors. Compos Sci Technol 2004;64:1915-9.

[30] Mäder E, Rausch J, Schmidt N. Commingled yarns - processing aspects and tailored surfaces of polypropylene/glass composites. Compos A Appl Sci Manuf 2008;39:612-23.

[31] Rausch J, Mäder E. Health monitoring in continuous glass fibre reinforced thermoplastics: manufacturing and application of interphase sensors based on carbon nanotubes. Compos Sci Technol 2010;70:1589-96.

[32] Rausch J, Mäder E. Health monitoring in continuous glass fibre reinforced thermoplastics: tailored sensitivity and cyclic loading of CNT-based interphase sensors. Compos Sci Technol 2010;70:2023-30.

[33] Warrier A, Godara A, Rochez O, Mezzo L, Luizi F, Gorbatikh L, et al. The effect of adding carbon nanotubes to glass/epoxy composites in the fibre sizing and/or the matrix. Compos A Appl Sci Manuf 2010;41:532-8.

[34] Wichmann MHG, Sumfleth J, Gojny FH, Quaresimin M, Fiedler B, Schulte K. Glass-fibre-reinforced composites with enhanced mechanical and electrical properties - benefits and limitations of a nanoparticle modified matrix. Eng Fract Mech 2006;73:2346-59.

[35] Díez-Pascual AM, Ashrafi B, Naffakh M, González-Domínguez JM, Johnston A, Simard B, et al. Influence of carbon nanotubes on the thermal, electrical and mechanical properties of poly(ether ether ketone)/glass fiber laminates. Carbon 2011;49:2817-33.

[36] Ashrafi B, Díez-Pascual AM, Johnson L Genest M, Hind S, Martinez-Rubi Y, et al. Processing and properties of PEEK/glass fiber laminates: effect of addition of single-walled carbon nanotubes. Compos A Appl Sci Manuf 2012;43: 1267-79.

[37] Shen Z, Bateman S, Wu DY, McMahon P, Dell'Olio M, Gotama J. The effects of carbon nanotubes on mechanical and thermal properties of woven glass fibre reinforced polyamide- 6 nanocomposites. Compos Sci Technol 2009;69: 239-44.

[38] Díez-Pascual AM, Gomez-Fatou MA, Ania F, Flores A. Nanoindentation assessment of the interphase in carbon nanotube-based hierarchical composites. J Phys Chem C 2012;116:24193-200.

[39] Díez-Pascual AM, Gonzalez-Dominguez JM, Martinez MT, Gomez-Fatou MA. Poly(ether ether ketone)-based hierarchical composites for tribological applications. Chem Eng J 2013;218:285-94.

[40] Zhu J, Imam A, Crane R, Lozano K, Khabashesku VN, Barrera EV. Processing a glass fiber reinforced vinyl ester composite with nanotube enhancement of interlaminar shear strength. Compos Sci Technol 2007;67:1509-17.

[41] Thakre PR, Lagoudas DC, Riddick JC, Gates TS, Frankland SJV, Ratcliffe JG, et al. Investigation of the effect of single wall carbon nanotubes on interlaminar fracture toughness of woven carbon fiber-epoxy composites. J Compos Mater 2011;45:1091-107.

[42] Qian H, Bismarck A, Greenhalgh ES, Shaffer MSP. Carbon nanotube grafted carbon fibres: a study of wetting and fibre fragmentation. Compos A Appl Sci Manuf 2010;41:1107-14.

[43] Qian H, Bismarck A, Greenhalgh ES, Shaffer MSP. Carbon nanotube grafted silica fibres: characterising the interface at the single fibre level. Compos Sci Technol 2010;70:393-9.

[44] Suraya AR, Yunus R, Nor Azowa I. Growth of carbon nanotubes on carbon fibres and the tensile properties of resulting carbon fibre reinforced polypropylene composites. J Eng Sci Technol 2009;4:400-8.

[45] Hapuarachchi TD, Peijs T. Multiwalled carbon nanotubes and sepiolite nanoclays as flame retardants for polylactide and its natural fibre reinforced composites. Compos A Appl Sci Manuf 2010;41:954-63.

[46] Li J. Bai T. The addition of polyethylene/polyamine surface treated carbon nanotube on the interfacial adhesion of carbon fiber reinforced polyimide composites. Polym Plast Technol Eng 2011;50:1393-7.

[47] Zhang JG. The effect of carbon fibers and carbon nanotubes on the mechanical properties of polyimide composites. Mechanics Compos Mater 2011;47: 447-50.

[48] Meszaros L, Gali IM, Czigany T, Czvikovszky T. Effect of nanotube content on mechanical properties of basalt fibre reinforced polyamide 6. Plast Rub Compos 2011;40:289-93.

[49] Ruiya R, Zhenhua L, Yunxuan L, Chilan C. Mechanical and tribological properties of polyimide composite reinforced with carbon fibers and carbon nanotube. Adv Mater Res 2011;311-313:189-92.

[50] http://www.victrex.com/docs/datasheets-docs/.

[51] http://www.solvayplastics.com/.

[52] Karnik SR, Gaitonde VN, Mata F, Davim JP. Investigative study on machinability aspects of unreinforced and reinforced PEEK composite machining using ANN model. J Reinf Plast Compos 2008;27:751-68.

[53] Shekar RI, Rao PMD, Siddaramaiah, Padaki VC, Kim NH, Lee JH. Fibre-fibre hybrid composites for aerospace applications. Adv Mater Res 2010;123125:1231-4.

[54] Shekar RI, Kotresh TM, Prasad ASK, Rao PMD, Kumar MNS, Siddaramaiah. Hybrid fiber fabric composites from poly ether etherketone and glass fiber. J Appl Polym Sci 2010;117:1446-59.

[55] http://www.rtpcompany.com/info/data/. 
[56] http://www.polyone.com/en-us/Pages/.

[57] Yang H, Liu J, Ji M, Yang S. Novel thermoplastic polyimide composite materials. In: El-Sonbati AZ, editor. Thermoplastic-Composite materials, Intechn; 2012. $<$ http://www.intechopen.com>.

[58] Li J. Effect of silane coupling agent on the tensile properties of carbon fiberreinforced thermoplastic polyimide composites. Polym Plast Technol Eng 2010;49:337-40.

[59] http://www.celanese.com/ticona/.

[60] http://akro-plastic.com/en/115/products.html.

[61] BASF Corporation. An advanced high modulus (HMG) short glass-fiber reinforced nylon 6: Part ll mechanical performance. Technical report, pape number: 2003-01-1123; $2003 . \quad<$ http://www2.basf.us//PLASTICSWEB/ displayanyfile?id=0901a5e180004883>.

[62] http://www.lnp.com.

[63] Han K, Liu Z-], Yu M-H. Preparation and mechanical properties of long glass fiber reinforced PA6 composites prepared by a novel process. Macromol Mater Eng 2005;290:688-94.

[64] Yoo Y, Spencer MW, Paul DR. Morphology and mechanical properties of glass fiber reinforced Nylon 6 nanocomposites. Polymer 2011;52: 180-90.

[65] http://www.tpcomposites.com/.

[66] Lin C-W, Lou C-W, Huang C-H, Juang C-L, Lin J-H. Electromagnetically shielding composites made from carbon fibers, glass fibers and impact-resistant polypropylene: manufacturing technique and evaluation of physical properties. J Thermoplast Compos Mater; 2013 [in press]. doi:10.1177] 0892705712473624

[67] Huang Z-Y, Chen Y-H, Tang J-H, Li Z-M. Hierarchic structure and mechanical property of short glass fiber/isotactic polypropylene composites containing $\beta$ nucleation agent. Polym Plast Technol Eng 2013;52:80-9.

[68] Kumar S, Bhatnagar U, Ghosh AK. Development of long glass fiber reinforced polypropylene composites: mechanical and morphological characteristics. J Reinf Plast Compos 2007;26:239-49.

[69] Liping Z, Liyun C, Jianfeng H, Shen G. Effect of processing factors on flexura properties of Cf-HA/PMMA composites. J Reinf Plast Compos 2010;29: $1187-94$.

[70] Wang X, Chi Y, Cao Y. The effect of PTFE on the mechanical, friction, and wear properties of CF/PMMA composites. J Thermoplast Compos Mater; 2013 [in press]. doi: $10.1177 / 0892705712470264$.

[71] Nguyen HX, Ishida AH. Poly(aryl-ether-ether-ketone) and its advanced composites: a review. Polym Compos 1987;8:57-73.

[72] Díez-Pascual AM, Naffakh M, González-Domínguez JM, Anson A, MartinezRubi Y, Martinez MT, et al. High performance PEEK/carbon nanotube composites compatibilized with polysulfones-l. Structure and therma properties. Carbon 2010;48:3485-99.

[73] Díez-Pascual AM, Naffakh M, González-Domínguez JM, Anson A, MartinezRubi Y, Martinez MT, et al. High performance PEEK/carbon nanotube composites compatibilized with polysulfones-II. Mechanical and electrical properties. Carbon 2010;48:3500-11.

[74] Wang S, Qiu J. Enhancing thermal conductivity of glass fiber/polymer composites through carbon nanotubes incorporation. Compos B Eng 2010;47:533-6.

[75] Assael MJ, Antoniadis KD, Metaxa IN. Measurement of the enhancement of the thermal conductivity of an epoxy resin reinforced with glass fiber and carbon multiwalled nanotubes. J Chem Eng Data 2009;54:2365-70.
[76] Kim YA, Kamio S, Tajiri T, Hayashi T, Song SM, Endo M, et al. Enhanced thermal conductivity of carbon fiber/phenolic resin composites by the introduction of carbon nanotubes. Appl Phys Lett 2007;90:093125-93127.

[77] John M], Thomas S. Biofibres and biocomposites-a review. Carbohydr Polym 2008;71:343-64.

[78] Wu S-H, Wang F-Y, Ma C-CM, Chang W-C, Kuo C-T, Kuan H-C, et al Mechanical, thermal and morphological properties of glass fiber and carbon fiber reinforced polyamide- 6 and polyamide-6/clay nanocomposites. Mater Lett 2001;49:327-33.

[79] Vlasveld DPN, Daud W, Bersee HEN, Picken S]. Continuous fibre composites with a nanocomposites matrix: improvement of flexural and compressive strength at elevated temperatures. Compos A Appl Sci Manuf 2007;38:730-8.

[80] Green K], Dean DR, Vaidya UK, Nyairo E. Multiscale fiber reinforced composites based on a carbon nanofiber/epoxy nanophased polymer matrix: synthesis, mechanical, and thermomechanical behaviour. Compos A Appl Sci Manuf 2009;40:1470-5.

[81] Kim M, Park Y-B, Okoli O, Zhang C. Processing, characterization, and modeling of carbon nanotubes-reinforced multiscale composites. Compos Sci Technol 2009;69:335-42.

[82] Díez-Pascual AM, Naffakh M, Gomez MA, Marco C, Ellis G, Martinez MT, et al. Development and characterization of PEEK/carbon nanotube composites. Carbon 2009;47:3079-90.

[83] Tsai C-h, Zhang C, Jack DA, Liang R, Wang B. The effect of inclusion waviness and waviness distribution on elastic properties of fiber-reinforced composites. Compos B Eng 2011;42:62-70.

[84] Halpin JC, Kardos JL. The Halpin-Tsai equations: a review. Polym Eng Sci $1976 ; 16: 344-52$.

[85] Fragneaud B, Masenelli-Varlot K, Gonzalez-Montiel A, Terrones M, Cavaillé JY. Mechanical behavior of polystyrene grafted carbon nanotubes/polystyrene nanocomposites. Compos Sci Technol 2008;69:3265-71.

[86] Thomas WF. Factors affecting the impact strength of glass-fibre-reinforced polyester composites. Composites 1973;4:105-10.

[87] Karapappas P, Vavouliotis A, Tsotra P, Kostopoulos V, Paipetis A. Enhanced fracture properties of carbon reinforced composites by the addition of multiwall carbon nanotubes. J Compos Mater 2009;43:977-85.

[88] Garcia EJ, Wardle BL, Hart AJ, Yamamoto N. Fabrication and multifunctional properties of a hybrid laminate with aligned carbon nanotubes grown in situ. Compos Sci Technol 2008;68:2034-41.

[89] Kim KJ, Kim J, Yu W-R, Youk JH, Lee J. Improved tensile strength of carbon fibers undergoing catalytic growth of carbon nanotubes on their surface. Carbon 2013;54:258-67.

[90] Qian H, Bismarck A, Greenhalgh ES, Kalinka G, Shaffer MSP. Hierarchical composites reinforced with carbon nanotube grafted fibers: the potential assessed at the single fiber level. Chem Mater 2008;20:1862-9.

[91] Tjong SC, Liang GD, Bao SP. Electrical behavior of polypropylene/multi-walled carbon nanotube nanocomposites with low percolation threshold. Scripta Mater 2007;57:461-4.

[92] Fiedler B, Gojny FH, Wichmann MHG, Bauhofer W, Schulte K. Can carbon nanotubes be used to sense damage in composites? Ann Chim Sci Mater 2004;29:81-94.

[93] McCrary-Dennis M, Okoli OI, Zeng C. Development of the displaced foam dispersion technique for the manufacture of multiscale composites. In: 18th International conference on composite materials (ICCM), Jeju Island, Korea; 2011. 